\title{
Does tomato breeding for improved performance under LED supplemental lighting make sense?
}

\author{
Aina E. Prinzenberg $(\mathbb{D} \cdot$ Hanneke van der Schoot - Olivier van Deth · Theoharis Ouzounis •

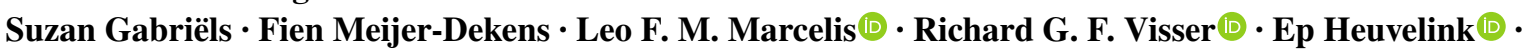 \\ Henk J. Schouten (i)
}

Received: 20 September 2021 / Accepted: 30 January 2022 / Published online: 14 February 2022

(C) The Author(s) 2022

\begin{abstract}
Differences in growth have been reported for tomato under LED compared to HPS light, however, it is not clear if breeding specific for LED supplemental light is worthwhile. Therefore, we derived four recombinant inbred line (RIL) tomato populations from parents with contrasting growth responses to different light spectra. These RIL populations were grown for four weeks under supplemental HPS or 95\% red and 5\% blue LED light in the greenhouse. For one population we also studied fruit production. Plant height and size of the side shoots of the young plants were strongly reduced under LED supplemental lighting compared to HPS in all populations. The adult plants showed shorter internode lengths, less trusses, less fruits, and lower yield of ripe fruits per plant under LED. However, when the unripe fruits at the last harvest day were included, the difference in
\end{abstract}

Supplementary Information The online version contains supplementary material available at https://doi. org/10.1007/s10681-022-02981-6.

A. E. Prinzenberg · H. van der Schoot · O. van Deth .

T. Ouzounis · S. Gabriëls · F. Meijer-Dekens ·

R. G. F. Visser · H. J. Schouten $(\bowtie)$

Plant Breeding, Wageningen University and Research, PO

Box 386, 6700 AJ Wageningen, The Netherlands

e-mail: henk.schouten@wur.nl

A. E. Prinzenberg - T. Ouzounis · L. F. M. Marcelis .

E. Heuvelink

Horticulture and Product Physiology, Wageningen

University and Research, PO Box 16,

6700 AA Wageningen, The Netherlands yield between HPS and LED disappeared, indicating that the plants under LED light were compacter and slower in development, but in the end produced similar yield. We found numerous QTL, but hardly any of these QTL appeared to be significantly LED-specific. Also, we found very significant genetic effects of maternally inherited plastids and mitochondria, showing the importance of using a parental genotype as mother or as father. However, these effects were very similar between the two light conditions. We conclude that our study does not justify tomato breeding programs that are specifically targeted at $95 \%$ red and $5 \%$ blue LED supplemental lighting.

Keywords LED · HPS - QTL · Maternally inherited plastids $\cdot$ Tomato $\cdot$ Side shoots

\section{Introduction}

Year-round tomato production in temperate climates with long winter periods of low light and low temperature requires greenhouses with supplemental lighting. Those are not only costly for the grower but also leave a large ecologic footprint due to the energy usage. The supplemental light is often provided by High Pressure Sodium (HPS) lamps that emit a warm, relatively broad light spectrum that proved favourable for many plant species. However, HPS lamps consume considerable amounts of energy. Narrow band Light-Emitting Diodes (LED) -lamps could be 
an alternative as these consume far less energy for the same light output (Gómez and Mitchell 2015; Kaiser et al. 2019). By providing the plants with a narrow spectrum of supplemental lighting, the lighting energy can be focussed on a more efficiently used light spectrum (Paradiso et al. 2011). Tomato plants grown in climate rooms under red and blue (RB) LED lighting had a higher $\mathrm{CO}_{2}$ assimilation rate than under white light from fluorescent tubes (Arena et al. 2016). However, the plants in the study of Arena et al. (2016) had, despite the higher $\mathrm{CO}_{2}$ assimilation rate, in RB-light a lower biomass compared to the white light control.

Light composition not only influences photosynthesis and biomass accumulation, but influences plant performance in many other ways: The concentration of soluble sugars is influenced by the quality of the light regime (Lanoue et al. 2017) which in turn is involved in oxidative stress signalling (Couée et al. 2006) and metabolic regulation (Smeekens et al. 2010). Photoreceptors, like phytochromes, influence flowering time (Strasser et al. 2010; Cao et al. 2015), and root and leaf growth (Rao et al. 2011; Costigan et al. 2011). The light regime under which plants grow also affects secondary metabolites (Carvalho and Folta 2014) and thereby could indirectly influence quality traits and disease resistance.

The genotype by environment interaction is important in the selection of the optimal spectral composition for a crop. Next to species specific responses (Bantis et al. 2018), natural variation for light responses was also identified between different tomato accessions (Ouzounis et al. 2016). In tomato, quantitative trait loci (QTL) for plant architecture that could influence light absorption in the canopy were identified (Nakano et al. 2016; Fulop et al. 2016) and also QTL for photosynthetic traits (Oyanedel et al. 2000; de Oliveira Silva et al. 2018) but light spectrum differences were not taken into account. Velez-Ramirez et al. (2014) identified a QTL for continuous light tolerance in tomato and developed from this a genotype that showed up to $20 \%$ higher yield when grown under continuous light. This study from Velez-Ramirez et al. is thus an example for the possibilities of genetic adjustments for light use efficiency in tomato. Nonetheless, there are, as far as we know, no QTL studies in tomato looking at light spectrum effects. Therefore, we aimed at identification of QTL that are LED or HPS specific.
Chloroplasts are critical in light perception and photosynthesis, and mitochondria are important for energy use. Chlorplasts and mitochondria are inherited from the mother, and contain their own genomes, and can thereby contribute to the genetic variation (Gray 1993). Therefore, we did not focus on genetic effects located in nuclei only (the QTL), but in addition we studied the effects of maternally inherited plastids and mitochondria. For this purpose, we made reciprocal crosses when developing F1 hybrids. Per combination of parents, half of the RILs were derived from F1 plants from Parent A x Parent B, whereas the other half of the RILs was derived from an F1 from the reciprocal cross Parent $\mathrm{B} \times$ Parent A. As a result, the first half of the RILs from this population harboured the plastids and mitochondria from Parent A, and the other half of the RILs contained the plastids from Parent B. We did this for all four RIL populations, leading to eight sub-populations.

We wondered if it makes sense to specifically optimize modern cultivars for LED supplemental lighting, by identification of LED specific QTL that could be used during breeding. We used tomato as a representative species for this study as tomato is often grown in protected conditions. We started the study by investigating the natural variation among light responses of 40 genotypes in climate rooms, focussing on the effects of red, blue and white LED light on biomass and physiological traits of these genotypes. Genotypes were selected with contrasting light reactions, crosses were made between these contrasting genotypes, and subsequently four different RIL populations were developed. We included reciprocal crosses, as these allowed the study of effects from maternally inherited plastids and mitochondria for each RIL population. We grew those populations in greenhouse conditions with supplemental HPS and LED light to identify physiological and morphological trait differences in the two light environments and investigated the underlying genetics by means of QTL mapping. We analysed four RIL populations in three replications in young plant stages and one RIL population of full-grown fruit yielding plants under HPS versus LED supplemental lightning, and genetically mapped plant growth and yield. 


\section{Materials and methods}

The initial 40 tomato accessions

In an initial experiment 40 tomato genotypes, including cultivars and wild accessions (Supplementary Table S1), were tested for their biomass under different lighting conditions (Ouzounis et al. 2016; Ji et al. 2020). These 40 accessions were grown in climate rooms (Ji et al. 2020) with artificial lighting. The plants were pre-grown in potting soil under fluorescent light for seven to nine days after sowing and then transferred to sterile river sand and grown in one of the following LED conditions: white light with additional UVB (ca. $0.16 \mathrm{~W} \mathrm{~m}^{-2}$ ) and FR (ca $26 \mu \mathrm{mol} \mathrm{m} \mathrm{m}^{-2} \mathrm{~s}^{-1}$ ) or R/B LEDs at a $16 \mathrm{~h}$ photoperiod (light intensities ca. $130 \mu \mathrm{mol} \mathrm{m} \mathrm{m}^{-2} \mathrm{~s}^{-1}$ ). The white light was created with white/red LEDs (GreenPower LED-TL-DR/W-MB-VISN, Philips, The Netherlands), and the additional UVB and FR was provided by Philips GreenPower LED production modules far-red (GreenPower LED -PM-FR-150), cool fluorescent tubes ( $38 \mathrm{~W}$, Philips) and Philips Broadband TL $20 \mathrm{~W} / 12$ RS Ultraviolet-B lamps. The R/B LEDs had $88 \%$ red light and $12 \%$ blue light (GreenPower LED-PM-DR/B-MB-150, Philips). The temperature and humidity of the climate room were approximately $22{ }^{\circ} \mathrm{C}$ and $70 \%$, respectively. Destructive measures for total dry biomass (roots, shoots and leaves) were done three weeks after transplanting.

Development of four RIL populations

From the 40 accessions, genotypes were selected that showed contrasting responses to the different light environments. The following four combinations of contrasting genotypes were selected for development of RIL populations: Ailsa Craig (LA2838A) and Kentucky Beefsteak (TR00021) hereafter abbreviated with "A K"; LA1578 (EA00674; S. pimpinellifolium) and Rutgers (EA00465; S. lycopersicum) "L R"; Moneymaker (CGN14330; S. lycopersicum) and Momotaro (Tough Boy; TR0003; S. lycopersicum) "Mm Mo"; and Kentucky Beefsteak (TR00021; S. lycopersicum) and NunhemsFM001 (S. lycopersicum) "K N". For each of these crosscombinations a reciprocal cross was performed, swapping the two parents, and therefore each RIL population consisted of two subgroups differing in maternally inherited plastids and mitochondria. All individuals of the populations were grown via single seed decent at least to the F5 generation (the Mm Mo RIL population was an F6). The F1 hybrids were made at Wageningen University and Research (WUR), whereas the RIL populations were developed in greenhouses in the Netherlands by Nunhems Netherlands B.V. (BASF Vegetable Seeds), Rijk Zwaan Nederland B.V., and Bejo Zaden B.V. For each subpopulation ca. 75 individual RILs were grown, leading to ca. 150 RILs per QTL analysis.

Growth conditions for the four RIL populations analysed in young stage

For the screening of the RIL populations, the plants were grown in glasshouses at Unifarm, Wageningen University and Research. In each experiment the same set of RILs was grown in parallel in two different compartments, one with HPS supplemental lighting and one with LED supplemental lighting.

Plants for both supplemental light treatments were germinated under HPS-supplemental lighting. Of each genotype ca. 12 seeds were sown. The seeds were placed on stone-wool plugs (Gro Plug, Grodan Rockwool B.V., Roermond, The Netherlands), covered with Agra-Vermiculite (PULL Rhenen, Rhenen, The Netherlands) and a transparent foil for additional humidity for approximately the first five days. The plugs were soaked with nutrient solution: $\mathrm{NH}_{4}$ $1.2 \mathrm{mM}, \mathrm{K} 7.2 \mathrm{mM}, \mathrm{Ca} 4 \mathrm{mM}, \mathrm{Mg} 1.82 \mathrm{mM}, \mathrm{NO}_{3}$ $12.4 \mathrm{mM}, \mathrm{SO}_{4} 3.32 \mathrm{mM}, \mathrm{P} 1 \mathrm{mM}, \mathrm{Fe} 35 \mu \mathrm{M}$ (as mixture of Fe-DTPA/Fe-EDDHSA), Mn $8 \mu \mathrm{M}$, Zn $5 \mu \mathrm{M}$, B $20 \mu \mathrm{M}, \mathrm{Cu} 0.5 \mu \mathrm{M}$ and Mo $0.5 \mu \mathrm{M}$. The macronutrients were provided as a mixture of fertilizers from Yara Benelux BV (Rotterdam-Vlaardingen, The Netherlands) and the micronutrients were from the Agrispoor product line of Horticoop BV (Bleiswijk, The Netherlands). The $\mathrm{pH}$ was between 5.5 and 5.8 (adjusted with $\mathrm{KOH}$ ) and the EC was approximately $2.0 \mathrm{dS} \mathrm{m}^{-1}$.

Seedlings with fully expanded cotyledons were selected for transfer after one week. The plants were transferred to $10 \mathrm{~cm} \times 10 \mathrm{~cm} \times 6 \mathrm{~cm}$ stone-wool blocks (Grodan Delta, Grodan Rockwool B.V., Roermond, The Netherlands). Upon transfer the plants were divided among the two compartments, one with supplemental HPS-lighting (Master green power, cgt $400 \mathrm{~W}$, Philips) and one with supplemental DR/LB 
LED-lighting (Green Power LED top lighting module DR/B LB, 190 W, Philips).

The light spectra of the lamps were measured (Supplementary Fig. S1) with a Field Spectroradiometer (SS-110, Apogee Instruments, Logan, UT, USA) and PSS values calculated according to the method of Sager et al. (1988). For the analysis, blue light over the wavelength range $400-500 \mathrm{~nm}$, green over 500-600 nm, red over 600-700 nm and FR over 700-800 nm were considered (individual intensity measures per wavelength were used for the average if above $0.05 \mu \mathrm{mol} \mathrm{s} \mathrm{m}^{-1}$ ). Percentages of those wavelengths in the spectrum were compared to the overall intensity in the PAR range from 400 to $800 \mathrm{~nm}$ and rounded to $5 \%$ intervals. To shield the experiment from light of adjacent compartments, the walls of the compartments were covered with white horticultural foil. The supplemental light intensity was about $200 \mu \mathrm{mol} \mathrm{s}{ }^{-1} \mathrm{~m}^{-2}$ (in a wavelength range from 400 to $700 \mathrm{~nm}$ ) during $16 \mathrm{~h}$, starting $16 \mathrm{~h}$ before sunset each day. The compartments were heated and set to an air temperature of $22{ }^{\circ} \mathrm{C}$ during the supplemental lighting period and of $19{ }^{\circ} \mathrm{C}$ outside the supplemental lighting time. Climate data inside the greenhouse were measured by a climate box (PT500 Temp./RH sensor, Hoogendoorn Automatisering) every $20 \mathrm{~s}$ and averaged over $5 \mathrm{~min}$ intervals. The incoming solar light and other environmental factors were recorded and averaged over time (Supplementary Table S2). The solar light was measured on top of the greenhouse. Eight light measurements (light meter LI250A from LI-COR) inside the empty greenhouse were taken at the approximate plant height on one day. With this data a coefficient between incoming light and the light measured on top of the glasshouse was calculated to estimate the incoming solar light for all experiments. In case the solar radiation (in the third and fourth experiment) outside the greenhouse was above $200 \mathrm{~W} \mathrm{~m}^{-2}$, an energy screen (Harmony 4215 $\mathrm{O}$ FR) was closed above the lamps in the greenhouse (leading to $42 \%$ less light at $100 \%$ screen-closure, the light-coefficient was adapted accordingly). For the mature plants the intensity of the solar light received by the plants was estimated using the measured solar radiation outside the greenhouse and a transmissivity factor of 0.62 (based on previous measurements). In addition, the measured solar radiation was reduced to $47 \%$, as this is the approximate amount of photosynthetically active photon flux density in the solar radiation; and then assuming that $1 \mathrm{~W} \mathrm{~m}^{-2}$ solar light equals $4.57 \mu \mathrm{mol} \mathrm{m}{ }^{-2} \mathrm{~s}^{-1}$ the conversion into $\mu \mathrm{mol}$ $\mathrm{m}^{-2} \mathrm{~s}^{-1}$ was done (McCree 1972; Britton and Dodd 1976).

The RILs of the populations $\mathrm{L} \sim \mathrm{R}, \mathrm{A} \sim \mathrm{K}$ and $\mathrm{Mm} \sim$ Mo were grown together in three, repeated experiments between October 2018 and March 2019 with one replicate per RIL and experiment, giving three replicates in time. The population $A \sim N$ was grown in one experiment in March/April 2019 with three replicates per RIL simultaneously. The seven parents of those RIL populations were grown in each experiment with four replicates. The first experiment was harvested 5 weeks after sowing and the consecutive three experiments were harvested in week 4 after sowing. The individual plants of each experiment were divided into four batches and sown on four consecutive days each on one ebb-and-flood table. Destructive measurements were performed during four consecutive days as well, so that the growthperiod was the same for all plants. All plants were distributed in a randomized design over the four tables. For the first three experiments the tables were divided into four areas (front, back and two middle parts of the rectangular tables) for the randomization pattern with similar numbers of plants from each RIL-population and reciprocal cross per area. From the parents one replicate was grown per table. The parents used for one population were situated close to each other on each table.

Plants were watered by flushing the stone-wool blocks for $5 \mathrm{~min}$ with nutrient solution (see above) on the ebb- and flood-tables. The watering schedule over the course of the experiment was irregular, it aimed at keeping the blocks always moist but not wet.

Phenotyping during the growth of the young plants

The operating quantum yield of electron transport of photosystem II ( $\Phi_{\mathrm{PSII}}$; "Phi PSII") was estimated, using the closed FluorCam 800MF (Photon Systems Instruments, Brno, Czech Republic) and a program to determine $\mathrm{Ft}$ under actinic light (ca. $200 \mu \mathrm{mol} \mathrm{s}{ }^{-1} \mathrm{~m}^{-2}$ ) and Fm (after max. light pulse) with the software FluorCam7 (version 1.2.4.4 Photon Systems Instruments, Brno, Czech Republic). The measurement was done four or five weeks after sowing on the second or third leaflet of a fully expanded leaf that was as much as possible perpendicular to the 
light. Measurements were done between 09.00 and 14.00 o'clock, alternating between the HPS supplemental light and LED supplemental light greenhouses approximately every 30 min (measuring batches of the same 22 genotypes in both HPS and LED supplemental lighting). Flavonol, anthocyanin and chlorophyll indices were obtained for all plants three weeks after sowing with the Force-A Dualex Scientific $+{ }^{\mathrm{TM}}$ sensor (Dynamax Inc., Houston, USA).

Destructive measurements of biomass related traits of the young plants

At the end of the growth period, four or five weeks after sowing (depending on the experiment), the plant stems were cut at the height of the stone-wool blocks and leaves were separated from the stem. In the axil of the true leaves (TL), side shoots developed in most genotypes. The numbers of true leaves and side shoots were counted separately from the second experiment onwards. The leaf/shoot-structures were counted in case they were longer than ca. $5 \mathrm{~mm}$ and the total respective fresh weights per plant determined. Final leaf area (of true leaves and side-shoots) was determined with an area meter (Li-cor, LI-3100C Area Meter, Li-cor Inc., Lincoln, Nebraska, USA). True leaves, side shoots and stems were put into separate paper bags and placed into a ventilated oven at $70{ }^{\circ} \mathrm{C}$ for $24 \mathrm{~h}$ followed by $105{ }^{\circ} \mathrm{C}$ for $24 \mathrm{~h}$, after which the dry weight was measured (in the first experiment the side shoot and true leaf dry weight was determined together, in all the following experiments separately). The specific leaf area (SLA) was determined as the ratio between leaf area and leaf dry weight.

\section{Growth conditions of the fruiting RIL population}

For the phenotyping of fruits of the RIL population "K N" ('Kentucky Beefsteak' NunhemsFM001) the plants were grown in glasshouses of Unifarm (Wageningen University and Research). The plants were sown in September 2020. The RIL population was chosen for the similar sizes and weights of their fruits of its parental lines, as well as the resistance to tomato mosaic virus (TMV) of the NunhemsFM001 parent. The plants were pre-grown for four and a half weeks on ebb and flood tables in a greenhouse. If within a $16 \mathrm{~h}$ light period the outside global radiation was below $250 \mathrm{~W} \mathrm{~m}^{-2}$, the natural light was supplemented with approximately $100 \mu \mathrm{mol} \mathrm{m} \mathrm{m}^{-2} \mathrm{~s}^{-1}$ HPS light. Subsequently, the plants were divided among two compartments of $12 \mathrm{~m}$ by $12 \mathrm{~m}$ each at a plant density of approximately 2.2 plants per $\mathrm{m}^{2}$. For avoidance of border effects, at each side of the greenhouse a border row of plants was grown. In both compartments about $220 \mu \mathrm{mol} \mathrm{m} \mathrm{m}^{-2} \mathrm{~s}^{-1}$ supplemental lighting was applied of either HPS in one compartment (Master green power, cgt $400 \mathrm{~W}$, Philips) or 95\% red and 5\% blue LEDs (Green Power LED top lighting module DR/B LB, $190 \mathrm{~W}$, Philips) in the other compartment. The light was measured ca $2.5 \mathrm{~m}$ over ground which was the height of the canopy top. The plants were kept at a height of approximately $2.5 \mathrm{~m}$ in order to keep $1 \mathrm{~m}$ of distance to the lamps above, and obtain equal light distribution. The duration of supplemental light was gradually increased, starting at five hours one month after sowing and reaching a maximum of $15 \mathrm{~h}$ of supplemental HPS/ LED light per day from four months after sowing onwards.

Stone-wool (Rockwool Grodan B.V., Roermond, The Netherlands) was used as planting medium, and the plants were drip-irrigated using the same nutrient solution as for the young plants. The EC of the nutrient solution in the stone wool slab was on average $3.8 \mathrm{ds} \mathrm{m}^{-1}$ under HPS versus $3.2 \mathrm{ds} \mathrm{m}^{-1}$ under LED. The compartments were heated if the temperature dropped below ca. $22^{\circ} \mathrm{C}$ (in a later stage of the experiment $24{ }^{\circ} \mathrm{C}$ ) during the supplemental lighting period or $19{ }^{\circ} \mathrm{C}$ outside the supplemental lighting time. In compartment with LED supplemental lighting, heating pipes below the plants and above the lamps were used, to compensate for the heat irradiance from the HPS lamps. The HPS compartment was only heated by pipes below the plants. For pollination we used bumblebees (Koppert, biological systems). Harvesting and measurements started in week 17 after sowing and continued up until week 28 . In each compartment the same set of 136 RILs was grown with one replicate each, as well as 11 replicates of each parent of the RIL population.

Growth abnormalities in the young RIL populations

The RIL populations were grown under two different supplemental lighting conditions in the greenhouse, under standard HPS lighting and R/B supplemental LED lighting. In some plants the formation of callus 
like structures starting at the veins on the abaxial side of leaves, called intumescence, was observed in both supplemental lighting conditions (Supplementary Fig. S2). Although all populations had individual plants with light intumescence symptoms (Williams et al. 2016), in some populations the occurrence was more severe. Intumescence was scored from 0 (no intumescence) to 3 (most of the leaves affected) and because this invasive physiological trait could affect other measured traits, genotypes that had a score of 2 and above were excluded from further analysis (0.1-19.2\% of all individual plants, depending on the population).

\section{Measuring fruit traits}

The number of fruit trusses was counted on week 17 and week 25 after sowing. The fruit trusses were labelled in order of development, starting at truss number 1 . The number of fruits were counted on week 17 and week 25 after sowing as well. Internode length was measured once during the trial on week 17 after sowing. This length was measured in centimetres from the third truss to the fifth truss. Fruit fresh weight was measured throughout the trial with intervals of three to four days between measurements, with the measurements starting in week 17 and ending in week 28 after sowing. The fresh fruits were measured from the breaker stage and onwards. This breaker stage is defined as the phase at which the fruit starts developing orange/red colour on its surface skin. During the last harvest during week 28 after sowing, all fruits were collected, including the non-ripe ones. By adding the weight of all unripe fruits per plant to the yield of ripe fruits of that plant, a total fruit yield (both ripe and unripe) was calculated per plant. By taking the number of fruits per plant into account, the average fruit weight per plant was obtained. Dry weight was measured for fruits from the 3rd and the 5 th truss. This was done by cutting the fruits and subsequent drying the cut pieces in a ventilated oven for the first $12 \mathrm{~h}$ at $70{ }^{\circ} \mathrm{C}$ and followed for at least $84 \mathrm{~h}$ at $105{ }^{\circ} \mathrm{C}$. Subsequently the weight of the dried fruit was determined.

Genotyping of the RIL populations

The four RIL populations were genotyped by Bejo Zaden B.V., Rijk Zwaan B.V, and Nunhems
Nederlands B.V. The genotyping was done with 185 , 219, 183 and 177 KASP markers for the populations $\mathrm{A} \sim \mathrm{K}, \mathrm{L} \sim \mathrm{R}, \mathrm{Mm} \sim \mathrm{Mo}$, and $\mathrm{N} \sim \mathrm{K}$, respectively, with approximately $2.9 \%, 12.5 \%, 5.2 \%$, and $6.7 \%$ of the marker calls scored as heterozygous. The average inter-marker spacing across all chromosomes was $4.8 \mathrm{cM}, 5.7 \mathrm{cM}, 7.2 \mathrm{cM}$ and $4.7 \mathrm{cM}$ respectively for the four populations (calculated with the summary. map function of RQTL). The number of markers is similar or higher compared to other recent publications that determined QTL in tomato (Liu et al. 2016; Wen et al. 2019).

\section{Statistical analysis}

A Wilcoxon rank sum test was used to determine the significance of the light condition or reciprocal cross effect on the individual populations, using $\mathrm{R}$ (version 3.5.0; www.r-project.org). Descriptive statistics were done with the $\mathrm{R}$ package psych (version 1.8.4; Revelle 2018). All graphics were made with the $\mathrm{R}$ package ggplot2 (version 3.0.0; Wickham 2016). For the relative trait value in HPS and LED light, the trimmed mean under LED light, excluding the phenotypically upper $10 \%$ and lower $10 \%$ of individuals of each population (for $\mathrm{A} \sim \mathrm{K}, \mathrm{L} \sim \mathrm{R}$ and $\mathrm{Mm} \sim \mathrm{Mo}$ over three experiments), was expressed as percentage of the trimmed mean in HPS light $\left(\operatorname{Mean}_{\mathrm{LED}} * 100\right.$ / Mean $\left._{\text {HPS }}\right)$. For the relative trait range per population, the trimmed average (again with a fraction of 0.1 of extremes trimmed at each end) trait value of the top $10 \%$ and bottom $10 \%$ plants within each population was calculated, and the difference between those values in percent as (((top-bottom)/top)*100) was calculated. Equally the relative difference between the sub groups of the RIL population that were derived from the reciprocal crosses were calculated, by comparing the trimmed means per subgroup as ((HighGroupMean - Low $\left._{\text {GroupMean }}\right) / \quad$ High $\left._{\text {GroupMean }}\right) * 100$. A Shapiro-Wilk normality test per condition, population and experiment showed that nearly $2 / 3$ of the trait values were not normally distributed. Broad sense heritability was estimated by using the mean sum of squares values (Mean $\mathrm{Sq}$ ) from a two-factor ANOVA (type III SS) on the rank-transformed data, that uses the RIL-genotypes and the experiment as main factors or in case of the population " $\mathrm{K} \sim \mathrm{N}$ " from a single ANOVA with genotype as factor. The ANOVA was done with the R package car (version 3.0-0; Fox and 
Weisberg 2019). For the estimation of the heritability, we used the equation $\mathrm{H}^{2}=\sigma_{\mathrm{g}}^{2} /\left(\sigma_{\mathrm{g}}^{2}+\sigma_{\mathrm{e}}^{2}\right)$. The Mean $\mathrm{Sq}$ of the residuals was used as environmental variance $\left(\sigma_{\mathrm{e}}{ }^{2}\right)$ and ((Mean $\mathrm{Sq}_{\text {RIL-genotype }}-$ Mean $\left.\mathrm{Sq}_{\text {residuals }}\right)$ / replicate number) gave the genotypic variation $\left(\sigma_{\mathrm{g}}^{2}\right)$. To test for an interaction of the light treatments and the subgroups derived from the reciprocal crosses, a two-factor ANOVA on the rank transformed data was done as described above per population, using the subgroups and light-environment as interacting factors.

The QTL analysis was performed using the R package R/qtl (Broman et al. 2003; Broman and Sen 2009). The genetic map was based on the position information from the companies and re-calculated for each RIL population. A single QTL analysis was performed with the non-parametric mapping function for both the young and mature RIL populations, using individual values per experiment as input. However, in case of the young population $\mathrm{N} \sim \mathrm{K}$ for which all replicates were grown within the same experiment an average value per genotype was used for the QTL analysis. In addition, a single QTL analysis with the non-parametric mapping function was performed for differences in response under LED and HPS, using as parameter $\left(x_{\mathrm{LED}}-x_{\mathrm{HPS}}\right) / x_{\mathrm{HPS}}$. For the populations $\mathrm{A} \sim \mathrm{K}, \mathrm{L} \sim \mathrm{R}$ and $\mathrm{Mm} \sim \mathrm{Mo}$ we used the BLUE function from the $\mathrm{R}$ package polyqtlR (Bourke et al. 2021) in the following way: $\operatorname{BLUE}($ data $=$ data, model $=$ pheno $\sim$ geno, random $=\sim 1$ lexperiment, genotype. $\mathrm{ID}=$ "geno"). In case of the population $\mathrm{N} \sim \mathrm{K}$ the block in which the replicates were grown was used as random effect.

Also, a multiple QTL analysis was performed for the young populations with the multiple imputation method of Sen and Churchill (Sen and Churchill 2001) using rank transformed data as input, and in case of the first young three populations the experiment number was used as covariate. All permutation tests for LOD-thresholds/penalties were done with 1000 permutations. In the single QTL analysis, the LOD threshold was determined specifically per population, trait and condition. For the multiple QTL analysis, the automated stepwise procedure was used (assuming a maximum of 7 possible QTL) with a penalized LOD score criterion balancing heavy and light interaction penalties. For computational reasons the penalties were calculated based on one trait with a median level heritability under HPS light conditions in the population $\mathrm{N} \sim \mathrm{K}$. LED-specific QTL were selected based on the multiple QTL analysis for the young population. For the mature population, these were selected based on the single QTL analysis. For the young population, QTL on the same chromosome were considered different if their approximate 99\% Bayes credible intervals did not overlap. The significance of the QTL that were only identified under LED light was verified with an ANOVA for the effect of the allele distribution at the peak-marker on the phenotype under LED light. Also, the allele by lightcondition interaction of those LED-specific QTL was assessed with an ANOVA (using the peak marker and the light condition as interacting factors explaining the trait). For both ANOVAs the rank transformed data from the individual plants was used and for the young populations $\mathrm{A} \sim \mathrm{K}, \mathrm{L} \sim \mathrm{R}$ and $\mathrm{Mm} \sim \mathrm{Mo}$, the experiment number was used as a block factor. The phenotypic mean difference of the two QTL with significant allele by light interaction was tested with a Tukey HSD-test with the package Agricolae (De Mendiburu 2020).

\section{Results}

Selection of contrasting parental genotypes for the four RIL populations

In an initial study 40 cultivars and wild accessions (Supplementary Table S1) were compared on the basis of their total dry biomass in different light conditions. Contrasts between genotypes in different light conditions were used to select parents for crosses to construct RIL populations. In the two light conditions, i.e. R/B LED light and white LED light with UVB and FR, Moneymaker, Momotaro, Ailsa Craig and Kentucky Beefsteak were among the genotypes with the largest difference in biomass comparing plants growing in white light with plants growing in R/B light. Moneymaker and Kentucky Beefsteak had a higher biomass in R/B while Momotaro and Ailsa Craig had a higher biomass under the white light (Supplementary Fig. S3). In R/B light, Rutgers was among the genotypes with the highest biomass and LA1578 was among the genotypes with the lowest biomass. The genotype NunhemsFM001 had an approximately median biomass under both conditions and one of the smallest differences in biomass 
between the light treatments. It was in contrast to Kentucky Beefsteak which had one of the largest biomass in $\mathrm{R} / \mathrm{B}$ light and the largest difference in biomass when compared between the two light environments. Those contrasting genotypes were used to create four RIL populations: Ailsa Craig (LA2838A) and Kentucky Beefsteak (TR00021)), abbreviated as "A K"; LA1578 (S. pimpinellifolium) and Rutgers "L $\sim \mathrm{R}$ "; Moneymaker and Momotaro "Mm Mo"; and Kentucky Beefsteak and NunhemsFM001 "K N". In view of possible effects from chloroplasts and mitochondria on the light use efficiency under LED and HPS, and considering that the plastids and mitochondria are maternally inherited, for each RIL population two subgroups were made, by swapping the parents when making the F1 hybrids.
Young plants were compacter, and had smaller side shoots under LED

For each RIL population a relative trait value was calculated to compare LED to HPS, where the trimmed average trait value of the plants grown under HPS light represents $100 \%$ of the trait value (Fig. 1; Supplementary Fig. S4). Despite few traits that were most likely more affected by the seasonal changes than by the population, the overall trend between the populations' average light responses was similar. In all four populations, the plants grown under LED supplemental lighting had on average less biomass, were more compact, darker pigmented and had smaller side shoots with less biomass compared to plants grown under the standard HPS supplemental lighting. Among the different traits, the side shoot size and the height of the plants were lowest in LED light compared to HPS light. The leaf area of the side shoots under LED supplemental lighting was between 65 and $79 \%$ of

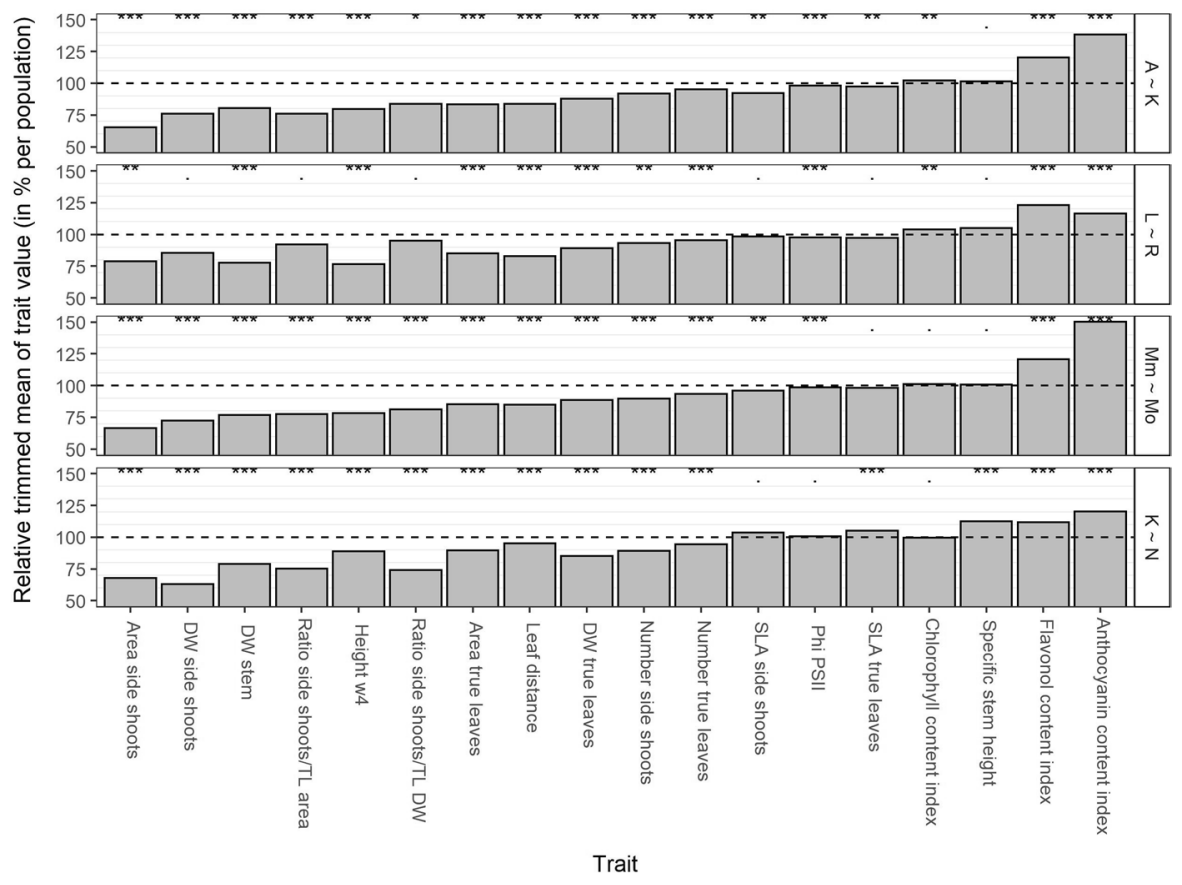

Fig. 1 Relative trait values for seedlings of the four RIL populations under LED compared to HPS supplemental light. Each RIL population was phenotyped in three replicates under LED and HPS supplemental lighting. The relative trait values express the trimmed mean under LED light compared to HPSsupplemental lighting (in \%) with the latter representing $100 \%$ of trait value. A significant difference in trait value between the light treatments $(* p$ value $<0.05 ; * * p$ value $<0.01 ; * * * p$ value $<0.001)$ is indicated per trait and population above each bar. For weight, area and leaf number only the data from the second and third experiment was used for the averages of the populations $\mathrm{A} \sim \mathrm{K}, \mathrm{L} \sim \mathrm{R}$ and $\mathrm{Mm} \sim \mathrm{Mo}$ 
that of plants under HPS lighting, depending on the RIL population. Likewise, the dry weight (DW) of the side shoots under LEDs was considerably lower, being $63 \%$ to $85 \%$ compared to those under HPS lighting. Moreover, the area and DW of the true leaves was lower under LED (between 84 to $90 \%$ of HPS). However, the reduction of the side shoots size and biomass was on average greater than that of the true leaves (TL), as the ratio of side shoots to true leaves was significantly smaller for plants grown under LED light compared to those under HPS (ratio side shoots/TL area, Ratio side shoots/TL DW; Fig. 1). Also the total number of leaves and side shoots was slightly but significantly lower for LED than HPS grown plants. The anthocyanin and flavonol content indices were in all populations between 12 and 50\% higher in LED compared to HPS grown plants. Chlorophyll content was in most populations also slightly increased in LED grown plants but overall similar between the conditions (Fig. 1). For all mentioned observations, we see a similar pattern for the parental genotypes (Supplementary Fig. S5). The efficiency of operating electron transport of photosystem II $\left(\Phi_{\mathrm{PSII}}\right)$ was 2-3\% lower in LED light compared to HPS in the first three experiments.
Side shoot size and plant height showed high heritability

We showed significant differences in overall trait values between HPS and LED supplemental light grown young plants. The ranges of the trait values within a RIL population were calculated by taking the relative difference between the highest and the lowest trait value, after removing the 10\% highest and 10\% lowest values (Fig. 2). Traits related to side shoots (area, SLA, DW) and anthocyanin content index, had the highest relative trait range compared to all other traits. These trends were independent of the light spectrum.

The range of the traits within a population shows the variability of the trait but not how much of the trait is genetically or environmentally driven. This genetic component of the phenotypic variation can be estimated by the heritability of the trait. Across all populations, the heritability estimate for side shoot size and plant height was the highest (up to 0.68 for side shoot area, 0.72 for the area ratio between side shoot and true leaves or 0.66 for plant height; Fig. 2), showing that those traits will be largely influenced by genetics. The lowest heritability was identified in all populations for $\Phi_{\mathrm{PSII}}$ and SLA (for side shoots as well as for true leaves). In the case of $\Phi_{\text {PSII }}$ it is possible that the light fluctuations in the greenhouse
Fig. 2 Relative trait range and heritability of different tomato populations. The coloured bars indicate the relative trait range between all genotypes within a population, calculated from the trimmed top and bottom $10 \%$ of all the plants in the population, indicating the percental difference between the lowest trait values compared to the highest. An estimate of broad sense heritability is shown as a colour gradient for each trait, population and light condition. The traits are sorted by their responsiveness to supplemental lighting quality

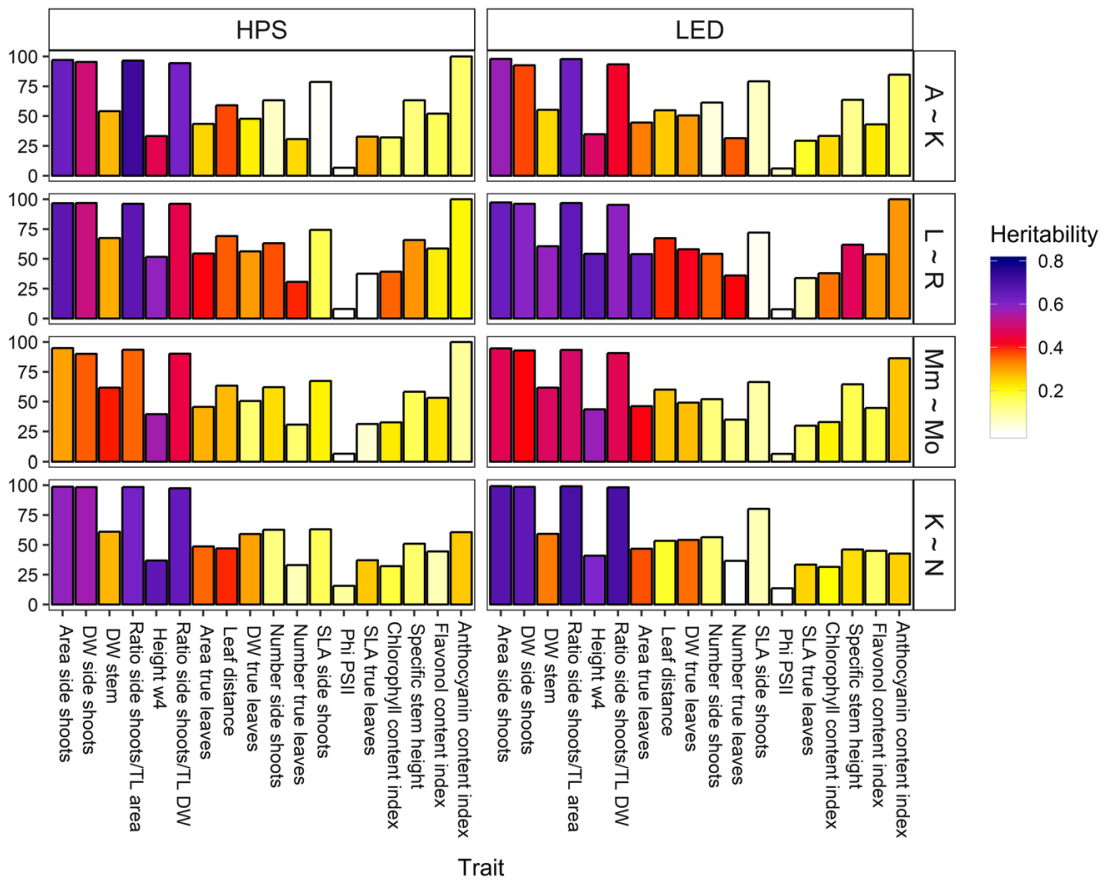


caused fluctuations in $\Phi_{\mathrm{PSII}}$ measurement that were confounding the analysis and thereby 'adding noise' to the genetics of the trait variation.

From these data we conclude that the largest variation and highest heritability were found for the size of the side shoots. This holds both for the absolute size and weight of the side shoots, and the relative size and relative weight compared to the main shoot. The height of the seedlings four weeks after sowing showed a reasonable variation, but a very high heritability. These conclusions hold for both light environments.
Genetic differences between maternally inherited plastids showed considerable impact on side shoots and plant size under both light conditions

Each RIL population consisted of two sub populations from reciprocal crosses, which means that half of a RIL population was derived from a cross between parent $\mathrm{A}$ and parent $\mathrm{B}(\mathrm{A} \times \mathrm{B})$, using $\mathrm{A}$ as mother and $B$ as father, whereas the other half of the population was derived from $\mathrm{B} \times \mathrm{A}$, in which parent $\mathrm{B}$ was used as mother and $\mathrm{A}$ as father. The rationale behind this was that photosynthesis and energy related processes occur for a large part in chloroplasts and mitochondria. These plant cell organelles are maternally inherited. Figure 3 shows that there was a clear impact of the reciprocal cross group on the evaluated traits, especially on plant size and architecture. The population in which the most traits were different between

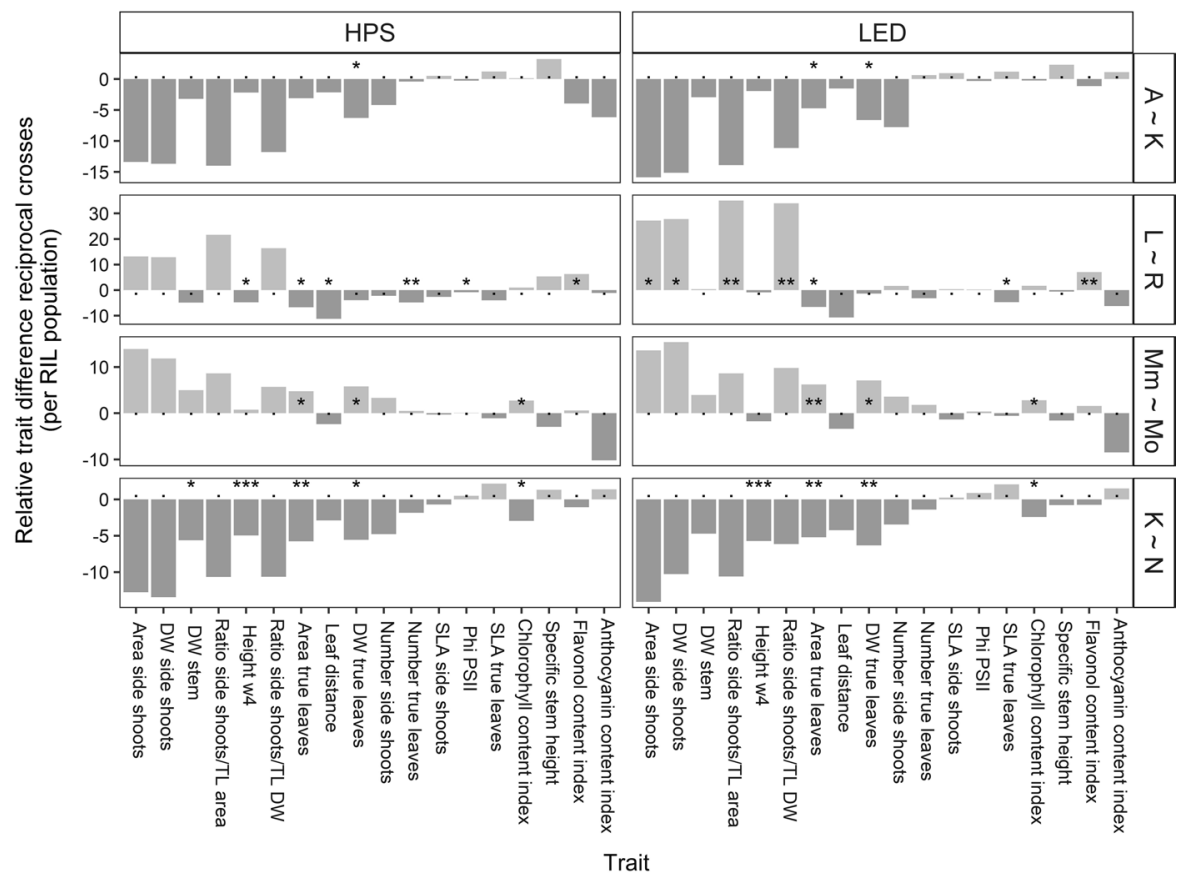

Fig. 3 Effects of maternally inherited plastids and mitochondria in the different tomato populations. For each combination of parents, two sub populations were derived, swapping the father and mother of the crossing. We refer to this as reciprocal crosses. The bars represent the trimmed mean difference between these subgroups of each RIL population. In the case that the bars are displayed as positive effect (light grey color), the sub-populations $\mathrm{A} \times \mathrm{K}, \mathrm{L} \times \mathrm{R}, \mathrm{Mm}$ (Moneymaker) $\times$ Mo (Momotaro) and $\mathrm{K} \times \mathrm{N}$ had the higher trait value (the parent that is named first in the crosses is the maternal line). Bars with negative effect value (dark grey) represent that the other maternally inherited plastids (sub-populations $\mathrm{K} \times \mathrm{A}, \mathrm{R} \times \mathrm{L}$, $\mathrm{Mo} \times \mathrm{Mm}$ and $\mathrm{N} \times \mathrm{K}$ ) gave the higher trait value. Significances of differences between the subgroups are indicated as follows: "." means no significant difference; * means $p$ value $<0.05$, $* * p$ value $<0.01$, and $* * * p$ value $<0.001)$. The traits are sorted by their responsiveness to supplemental lighting quality, and are divided by the supplemental lighting conditions, HPS or R/B LED light 
the sub populations, meaning strong effects of maternally inherited plastids, was $\mathrm{L} \sim \mathrm{R}$. The ratio of side shoots to true leaves was most affected in this population under LED-supplemental lighting. When the $S$. pimpinellifolium LA1578 was used as mother the side shoots were 35\% larger compared to using Rutgers (EA00465; S. lycopersicum) as mother. Apparently, the formation of side shoots is significantly under control of maternally inherited plastids in the $\mathrm{L} \sim \mathrm{R}$ population. For the $\mathrm{K} \sim \mathrm{N}$ RIL population the height of four-week-old seedlings was very significantly influenced by the maternally inherited organelles too: When N (S. lycopersicum NunhemsFM001) was the mother, the seedlings were $5 \%$ longer compared to K (S. lycopersicum Kentucky Beefsteak) as maternal parent. The plants were not only 5\% longer, the dry weight and area of the true leaves were also 5\% higher when the Nunhems accession was used as mother rather than as father. Apparently, the plant size was significantly influenced by the origin of the plastids in this population.

Remarkably, the maternal effects were very similar between the two light conditions. An ANOVA did not show any significant interactions between the light treatments and the subgroups (except for $\phi_{\text {PSII }}$ in the population $\mathrm{L} \sim \mathrm{R}$ with a significant interaction at a $p$ value of 0.03 ).

Numerous reproducible QTL for young plant traits under both LED and HPS, but hardly any differential light impact

Comparing the QTL detected in a single QTL analysis for all traits and populations, under HPS and LED light, showed that the distribution of QTL largely differed per population (Fig. 4). Detailed information about trait values, raw marker data, and the LODscores per trait are provided in the Suppl. Files 1 and 2. Related traits like the area and dry weight of the true leaves or side shoots, or the DW and height of the stem were often co-localizing for each population (Fig. 4). The QTL for true leaves and side shoots are at different locations. Although the location of most QTL differed between populations, the QTL for DW and area of the side shoots (and the related ratios of the side shoots to the true leaves) are co-locating in the populations that share Kentucky Beefsteak as a parent, i.e. $\mathrm{A} \sim \mathrm{K}$ and $\mathrm{K} \sim \mathrm{N}$. In both cases the presence of the Kentucky Beefsteak-allele at the QTL gave a lower trait value.

The QTL patterns within one population were overall similar for the two light conditions (Fig. 4). However, some QTL were only detected in one of the light conditions. The QTL that emerged only in LED light treatment with a multiple QTL analysis, and not at HPS supplemental light, are graphically represented per chromosome, population and trait in Fig. 5. More detailed information about the positions and LOD-scores can be found in the Suppl. File 2. Figure 5 shows in total 44 putative LED-specific QTL, with LOD scores between 1.4 and 11.3 and an explained variance between 1.8 and 17.2\% (Supplementary Fig. S6). We used an ANOVA to evaluate if the allelic effect at the QTL was significantly different for the two light conditions (interaction term in the ANOVA) beyond the overall difference in phenotype caused by the different lights. If the interaction would be significant, the allelic variation at the QTL can be useful for breeding for LED specific conditions. For only two out of those 44 QTL a significant $(p<0.05)$ allele by light interaction was determined i.e., for leaf distance (=internode length) in the population $\mathrm{Mm} \sim \mathrm{Mo}$, and for anthocyanin content index in the population $\mathrm{A} \sim \mathrm{K}$, although the differential impact was not very strong for these two QTL (Table 1).

As an alternative approach, the relative difference in trait value per genotype for the two light environments was calculated, using the expression $\left(x_{\mathrm{LED}}-x_{\mathrm{HPS}}\right) / x_{\mathrm{HPS}}$. Subsequently, we used this relative difference in light response in a QTL analysis. No QTL were identified for this response value for the populations $\mathrm{A} \sim \mathrm{K}, \mathrm{N} \sim \mathrm{K}$ and $\mathrm{L} \sim \mathrm{R}$ for the selected traits. For population Mm $\sim$ Mo the QTL for leaf distance on ch06 was identified again, with a peak LOD score of only 2.78 just above the threshold, confirming the weak LED specific QTL for this trait (Supplementary Fig. S7).

We conclude that we found many QTL in the four populations for the evaluated traits. Usually, these QTL appeared in both light environments, but 44 QTL could be LED specific when looking at the QTL graphs. However, a more robust statistical evaluation of these 44 QTL showed that the allelic effects were not significantly different for the two light conditions, apart from two exceptions. This means that only two small effect QTL were really LED-specific for the young plants. 

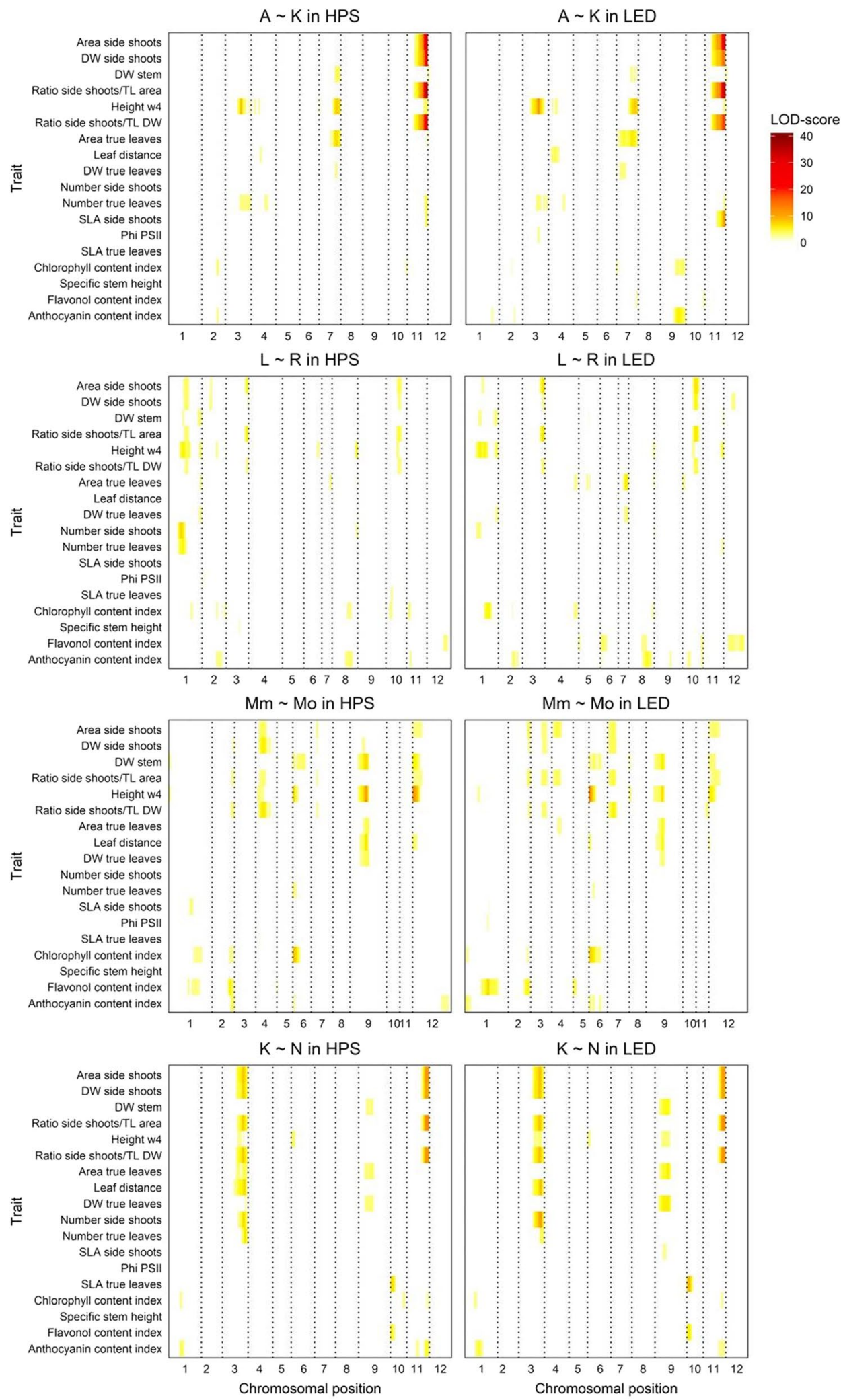
4Fig. 4 QTL pattern for the four different tomato RIL populations. The heatmaps show per population (from top to bottom) and condition, HPS (left) and LED (right), the LOD of QTL from a single QTL analysis. Only LOD scores above the trait specific LOD threshold are depicted. The $\mathrm{x}$-axis of each heatmap shows the genetic maps of the respective RIL population and the chromosomes (1-12, written from left to write) are separated by vertical, dotted lines. The traits are on the y-axis in the same order as the previous graphs. Detailed LOD values and intervals are provided in Suppl. File 2

LED reduced internode length, plant development, and number of fruits per plant, but eventually no yield reduction

For one out of the four RIL populations we also analysed fruit traits, namely for the $\mathrm{K} \sim \mathrm{N}$ population (Kentucky Beefsteak NunhemsFM001). The reason for selecting this population was that one parent (NunhemsFM001) is a recent variety and its performance represents better modern varieties than old varieties like Moneymaker do. In addition, the parents had similar fruit sizes, i.e. NunhemsFM001 $245.48 \pm 7.25 \mathrm{~g} /$ fruit and Kentucky Beefsteak $281.95 \pm 15.18 \mathrm{~g} /$ fruit under HPS light, which should prevent a very pronounced segregation of fruit size in the RIL population. This is relevant for analysing fruit yield.

We evaluated this fruiting RIL population under LED and HPS supplemental lighting. The population showed significantly $(p=0.02)$ shorter internode lengths under LED compared to HPS supplemental lighting in mature plants, $8 \%$ and $18 \%$ less trusses respectively in week $17(p=0.002)$ and week 25 $(p=1.0 \mathrm{e}-10), 8 \%$ and $17 \%$ less fruits during these weeks ( $p=0.018$ and $1.2 \mathrm{e}-05$, respectively), and $15 \%$ lower yield of ripe fruits per plant $(p=5.2 \mathrm{e}-07$, Figur.8, Supplementary File 3). However, when the unripe fruits at the last harvest day were included, the difference in yield between HPS and LED disappeared, indicating that the plants under LED light were a bit compacter, slower in development, but in the end produced similar yield.

Interestingly, the fraction of dry matter partitioned to the fruits was similar for HPS and LED. Furthermore, the average weight per fruit was $8 \%$ higher for LED, which was a significant difference $(p=0.035)$. Apparently, the lower number of fruits per plant under LED was compensated by a somewhat larger fruit size, giving a similar yield eventually.
High correlations between fruit traits

As expected, the number of trusses per plant in week 17 was highly correlated with the number of trusses in week 25 , and highly correlated with the number of fruits per plant during these weeks (Fig. 6). The weight per fruit was very clearly negatively correlated with number of fruits per plant (Fig. 6). There was a weaker positive correlation between the number of fruits and number of trusses at the one hand, and the total fruit yield (in kg per plant) at the other hand. The table also shows that the number of fruits per plant showed a higher correlation with yield than weight per fruit did. Both, number of trusses and weight per fruit, contribute to yield, but apparently, the number of trusses was a more important driver for yield.

Several major QTL for fruit traits under LED and HPS, but no convincing LED specific ones

To identify possible LED-specific QTL for the measured traits, a QTL analysis was performed on data from both lighting systems individually. Significant QTL were found on ch01 and ch11 for the following traits: number of trusses in week 17 and 25, number of fruits in these two weeks, and fresh weight per fruit (Fig. 7; Supplementary File 2). These five traits are physiologically closely related, showed therefore a high correlation (Fig. 7), and apparently are under control of the same QTL on ch01 and ch11. These two QTL emerged under both lighting conditions.

For the fruit yield (kg per plant) we found weak QTL on ch11 for HPS, and on ch01 and ch10 for LED (Fig. 7, Supplementary File 2). The presence of QTL under LED light, and absence of these QTL under HPS light, may indicate LED-specific QTL. To study this in more detail, we mapped the relative differences for these traits between the two lighting conditions, using the expression $\left(x_{\mathrm{LED}}-x_{\mathrm{HPS}}\right) / x_{\mathrm{HPS}}$. However, no light specific QTL were found, neither on ch01, nor on ch11 (Fig. 7C). For none of the five traits, LED-specific QTL emerged, showing the absence of a LED-specific QTL for number of trusses, number of fruits, and fresh weight per fruit in the $\mathrm{K} \sim \mathrm{N}$ population.

Also, for internode length and the dry matter fraction of the fruits we detected QTL with low LOD scores that seemed to be different between the 
Fig. 5 QTL that were only identified under LED light. The QTL that were only identified under LED conditions are presented as circles. The sizes represent the LOD scores. The colour of the circles indicates the significance of the allele by light-condition interaction of the peak marker of those QTL between HPS and LED light, determined by an ANOVA analysis. Detailed LOD values and intervals are provided in Suppl. File 2

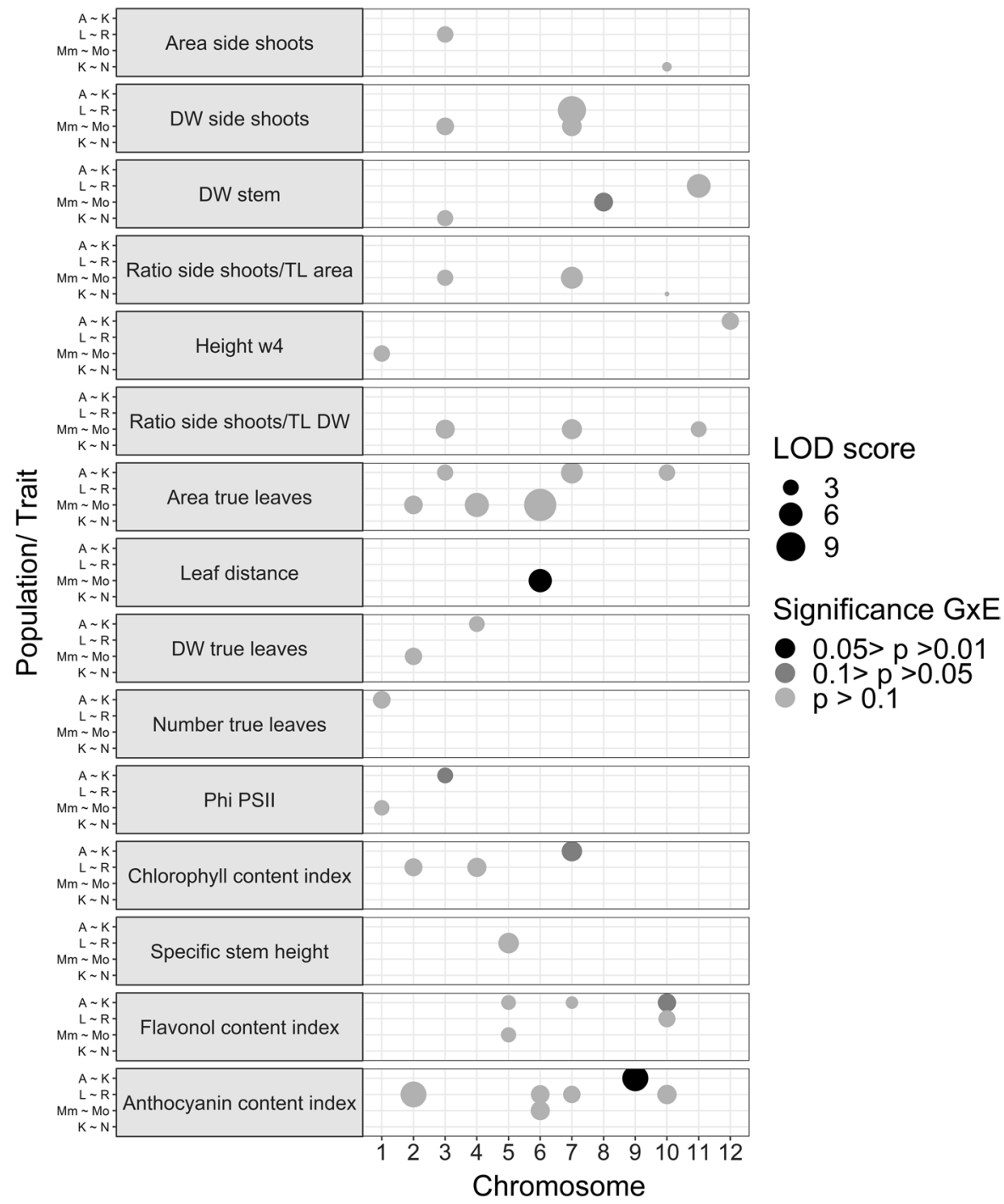

lightning conditions (Fig. 7A, B). However, again no QTL for the differential light effect was found (Fig. 7C).

We conclude that we were able to detect QTL for the different fruit traits and internode length, but none of these QTL appeared to be significantly specific to one light condition.

\section{Discussion}

We showed that there was a large phenotypic range for the evaluated traits of young plants and of fruiting plants, with varying degrees of genetic influences. Especially the architectural traits height and side shoot size showed high levels of heritability. Also other studies in tomato found a high heritability for architectural traits, especially height but also to varying degree for number of primary branches (Mohamed et al. 2012; Shankar et al. 2013; Taiana et al. 2015). For height, side shoot area, and weight of the young plants, QTL were identified in each population though there is a discrepancy between the explained variance by the QTL and the heritability estimate. This so called missing heritability can be explained by e.g. smaller effect QTL or interactions that are not detected by the analysis (Eichler et al. 2010; Yi 2010).

Between the young populations the identified QTL were mainly different, reflecting the diverse genetic 
Table 1 Allelic effect size and position of the two LED specific QTL with significant interaction between allelic variation and light condition

\begin{tabular}{lll}
\hline Population & A K & Mm Mo \\
\hline Trait & Anthocyanin content index & Leaf distance (cm) \\
Chromosome & 9 & 6 \\
Flanking marker & mTO3241773-mTO3245229 & SL06_09-SL06_08 \\
Physical interval (Mbp) & Ch09_SL2.5: 66.037-70.953 & Ch06_SL3.0: \\
& & $0.753-33.012$ \\
$P$ value of interaction term allele $\times$ light & 0.04 & 0.02 \\
Mean phenotype in HPS of allele: A or Mm & $0.020 \mathrm{c}$ & $2.59 \mathrm{ab}$ \\
Mean phenotype in HPS of allele: K or Mo & $0.023 \mathrm{c}$ & $2.72 \mathrm{a}$ \\
Mean phenotype in LED of allele: A or Mm & $0.027 \mathrm{~b}$ & $2.08 \mathrm{c}$ \\
Mean phenotype in LED of allele: K or Mo & $0.035 \mathrm{a}$ & $2.38 \mathrm{~b}$
\end{tabular}

Two LED-specifc QTL were identified for the growth of young plants of which the allelic variation at the QTL peak marker had a significant interaction with the light environment in an ANOVA model. Those two QTL were for anthocyanin content index and leaf distance (which is internode length). The effect per allele call, Ailsa Craig (A), Kentucky Beefsteak (K), Moneymaker (Mm) or Momotaro (Mo) is shown as mean phenotypic value with letters indicating significant different groups at an alpha of 0.05 honest significant difference test. For each QTL the flanking marker (approximate 99\% Bayes credible interval) and physical interval is given

Fig. 6 Correlations of traits of adult plants of the $\mathrm{N} \sim \mathrm{K}$ RIL population

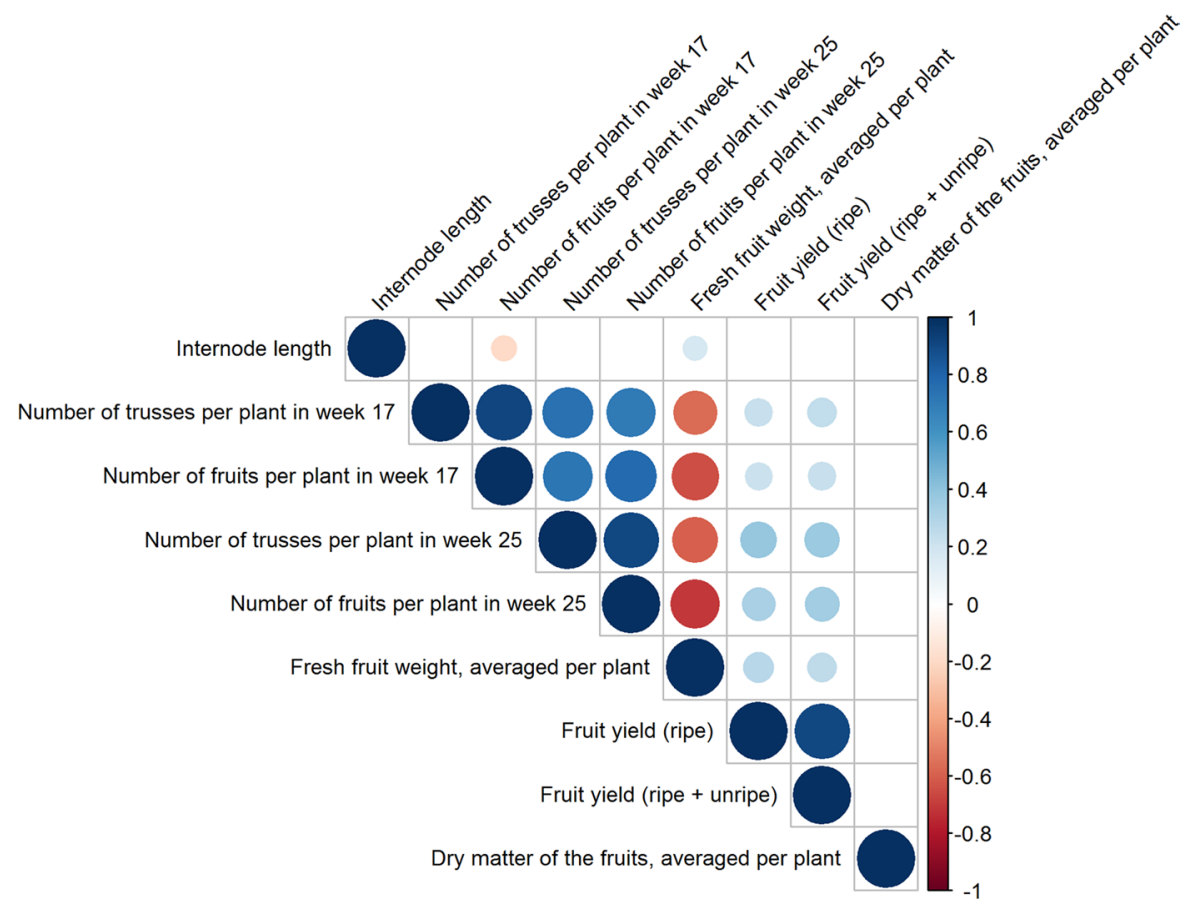

backgrounds used in this experiment. The parents of the RIL populations were selected according to their diverse light responses and the QTL identified were therefore largely specific to the respective genotypes. Only the populations with one common parent, Kentucky Beefsteak, showed co-locating QTL (for side shoot area and DW). Overall, this suggests a complex regulation of light responses and a large diversity among the evaluated accessions. We believe the series of QTL described in this study is reliable as for three of the four populations, the effect of three experimental replications was taken into account for the analysis and thereby minimizing the random environmental effects that could influence a QTL analysis in only one experiment. In addition, the similarity in QTL pattern (Fig. 4) between the two light conditions for 
Fig. 7 QTL analysis of adult plants of the $\mathrm{N} \sim \mathrm{K}$ population in a greenhouse with A HPS supplemental lighting; B LED supplemental lighting. Only significant LOD scores are shown. At the horizontal axis, positions of the 177 markers on tomato chromosomes 1-12 are shown. C QTL analyses of the relative differences in trait values under LED compared to HPS. No significant QTL appeared here

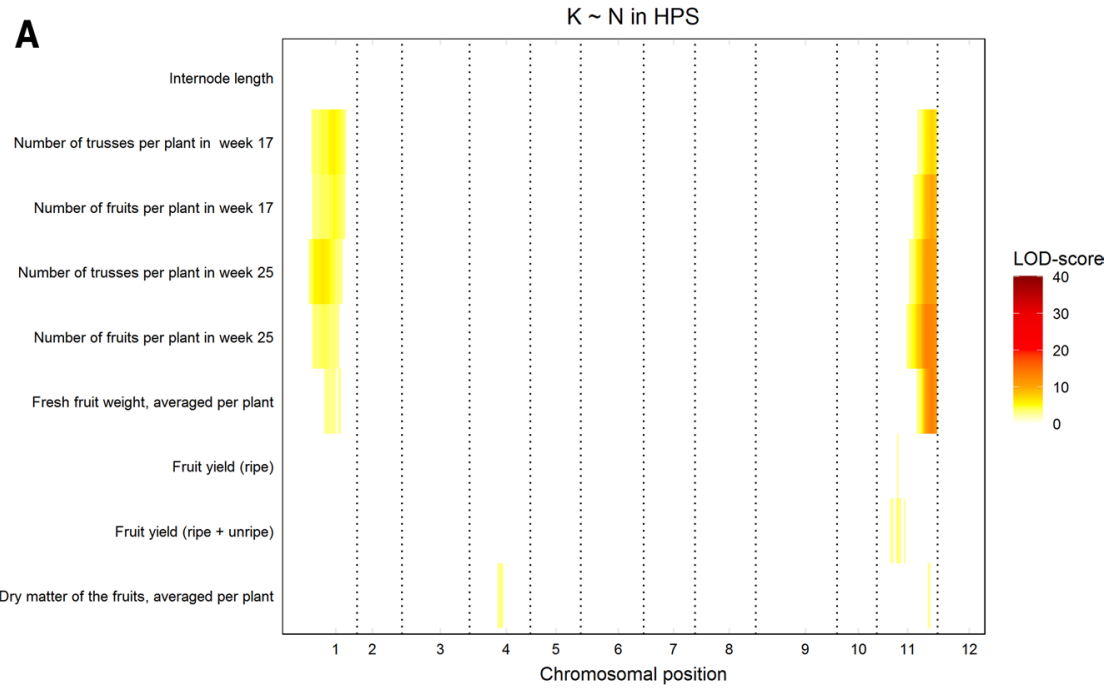

B $\mathrm{K} \sim \mathrm{N}$ in LED

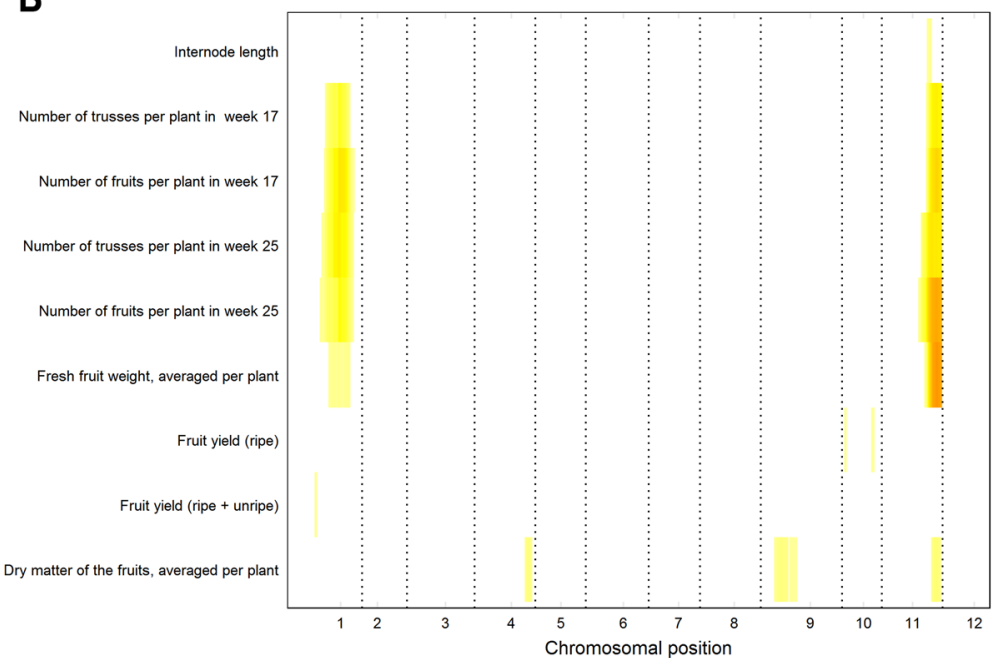

C

$\mathrm{K} \sim \mathrm{N}$ comparison HPS-LED

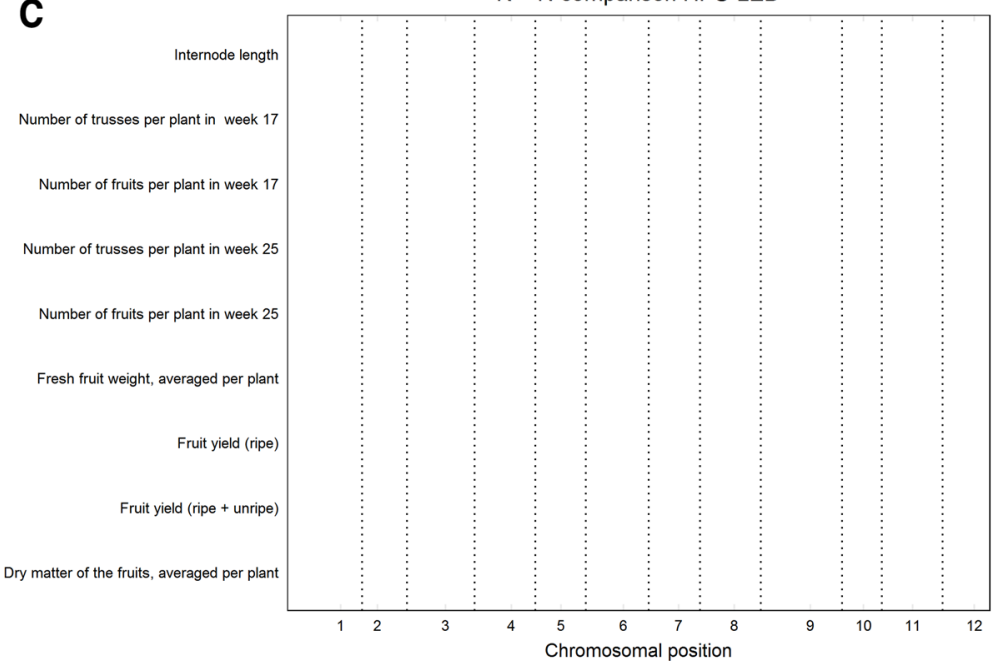


young plants shows not only the similar genetic control in both light setups but further also the reproducibility of the data, obtained from parallel experiments.

The overall trait ranges and heritabilities were considerably consistent across populations and light conditions. There were a few differences, especially between the populations tested in the first three experiments compared to the population $\mathrm{K} \sim \mathrm{N}$ that was tested in the fourth experiment. These differences may have resulted from the increased solar light period and higher light intensity during the fourth experiment. Though there was a strong impact of the light spectrum on the overall plant performance, the QTL patterns for most traits were similar between the conditions within one population. Only two QTL out of the 44 LED-specific QTL were found to have a significant interaction with the light environment, which points to a general shift in phenotype in the different light conditions, but all tested genotypes responded in a similar way. Also Wolyn et al. (2004) studied an A. thaliana RIL population in five different light qualities for hypocotyl length and out of eight QTL only one QTL, specific for red light, was found to have a significant genotype by environment interaction. So, although the parental accessions of our RIL population were selected based on differences to light responses, the data on the RIL populations gave no strong indication for a differential interaction between the tested tomato genotypes and the two light conditions. The difference in environmental response between these greenhouse experiments and the first ones in the growth chamber may be explained by the more fluctuating environmental conditions and additional solar light in the greenhouse.

For one RIL population we also studied fruit traits. The number of fruit trusses per plant, number of fruits per plant, and average weight per fruit per plant showed a strong genetic impact with clear QTL on ch01 and ch11. These traits could be linked to the fruit weight 11.3 (fwl1.3) or fasciated (fas) loci, which have been shown to be located at the bottom of ch11 in different tomato cultivars (Huang and van der Knaap 2011). The presence of the loci increase fresh fruit weightby increasing mesocarp size ( $f w 11.3$ ) or the locule number of the fruit (fas; Lippman and Tanksley 2001; Cong et al. 2008; Mu et al. 2017), one of those factors could explain the QTL on ch11. The QTL on ch01 might be linked to a locus similar to fw11.3 or fas, possibly the fruit weight 1.1 (fwl.1) locus (Lippman and Tanksley 2001; Hernández-Bautista et al. 2015), as the QTL on ch01 has a similar pattern as the QTL on ch11 (Fig. 7).

Next to the nuclear genome, the organelle genomes in the mitochondria and plastids carry genetic information (Gray 1993) which is passed on via the maternal line to the offspring. The organelle genomes contribute to plant performance and environmental responses, e.g. plastome gene expression can be light regulated (Yen et al. 1997; Lupaşcu et al. 2015; Facella et al. 2016). Although a number of spontaneous chloroplast mutations were described (Massouh et al. 2016), there may be little variation in plastomes of modern tomato cultivars (Kahlau et al. 2006; Raime and Remm 2018). Similar intraspecific studies for the mitochondrial genome of tomato are missing but the mitogenome is less conserved than the plastome and intraspecific variation for different species was shown (Sloan et al. 2012; Kim and Lee 2018). The effects from the reciprocal crosses varied between the populations, and the sizes of these effects were lower compared to the overall genetic trait range. Plastid and mitochondrial specific metabolic processes were found to influence axillary bud break by providing energy as well as metabolites that act in the light induced phytohormonal signalling (Mason et al. 2014; Signorelli et al. 2018). This important role of the organelles in bud outgrowth could explain the differences we observed in side shoot formation between the two sub-groups from reciprocal crosses. Chloroplasts are critical in light perception and photosynthesis, and therefore genetic differences in chloroplasts might lead to differences in responses to HPS and LED supplemental light. However, we did not observe this in our experiments, as clear interactions between supplemental lighting and reciprocal crosses were not found.

Across all RIL populations, the plants were more compact and had less biomass under LED compared to the standard HPS supplemental lighting in the greenhouse. Specifically, they had shorter internodes, the biomass and leaf area were reduced, while the specific stem height was identical to growth under HPS. Also, the fruiting population showed significant shorter internodes under LED compared to HPS supplemental lighting. HPS lamps emit more far red (FR) light than the LEDs, with a phytochrome stationary state values of 0.852 for HPS vs 0.883 for LED. Low ratios of R/FR light and corresponding lower 
phytochrome stationary state (PSS) values can lead to plant elongation. Previous studies showed that R/B LED supplemental lighting led to compacter growth compared to HPS and R/B lighting with FR (Hogewoning et al. 2012). Decreasing PSS values from 0.88 to 0.80 increased stem height, leaf area, and total dry weight (Kalaitzoglou et al. 2019). Our data confirm that this is a common trend amongst a wider range of tomato genotypes. The lower PSS values may explain the taller stems and thinner leaves with a larger leaf area under HPS-supplemental lighting in our study.

Higher levels of green light or lower blue to green ratios were implicated in e.g. shade avoidance (Zhang et al. 2011; Fraser et al. 2016) that also lead to hypocotyl and maybe (early) stem elongation (Folta 2004; Sellaro et al. 2010). Therefore, the green light in the HPS lamps (ca. 50\%) may also play a role in the morphological differences compared to LED light. Another factor that could affect the plant growth was that the HPS emit radiative heat, the broad range HPS radiation has more infrared light and may lead to a higher meristem temperature at the top of the plants. This could favour leaf initiation and outgrowth. We have seen a slightly higher leaf number under HPS light, which could be a meristem temperature effect (Savvides et al. 2016).

Most striking for the young plants were the sizes of the side shoots compared to the true leaves, both regarding high heritability and difference between the light conditions. When looking at side shoot formation we should subdivide into axillary bud outgrowth that breaks its quiescence, and consecutive side shoot development. The first could be indicated in our study by the number of side shoots and the second by the overall size and dry weight of these side shoots. The number of axillary buds was less affected than the size of the side shoots by the different supplemental lighting conditions. Tucker (1976) proposed that far red triggers abscisic acid formation near the auxiliary bud and thereby inhibits it outgrowth. He showed that a pulse of far red light stunts side shoot formation in young tomato plants. Generally, a low R/ FR ratio can favour apical growth instead of side shoot growth (Girault et al. 2008; Evers et al. 2011; Dierck et al. 2017). The R/FR ratio is higher in the LEDcompartment, so we would expect more side shoots there than under HPS supplemental lighting. These assumptions conflict with our experimental outcome of less and smaller side shoots in LED light. Blue light was also found to impact axillary bud outgrowth but the effect seems to vary between species and genotypes (Leduc et al. 2014; Huché-Thélier et al. 2016). However, the percentage of supplemental blue light is similar between our two conditions (ca. 5\% in both). Therefore, also other light quality differences seem to impact side shoot outgrowth. In our experiments, this could be a lower blue/red ratio (0.03 in compared to 0.12 ) or the lack of green light in LED supplemental lighting.

The significantly elevated levels of anthocyanin content in the plants grown under LED light compared to HPS light could indicate stress (ChalkerScott 1999; Kovinich et al. 2015). It is not easy to determine if a plant is in an optimal growing condition or stressed state. The reduction of $\phi_{\mathrm{PSII}}$ is a possible stress indicator. In three of the four populations $\phi_{\text {PSII }}$ was indeed lower in LED than HPS grown plants, however the difference was minor and the $\phi_{\text {PSII }}$ was with an average of 0.7 (over all populations and experiments) still at a healthy level. In addition, the plants grew otherwise visually normally. Studies in Arabidopsis showed phytochrome induced upregulation of anthocyanin inducing genes with increasing red light (Shin et al. 2007; Liu et al. 2015). Red light was overrepresented in LED compared to HPS supplemental lighting, activating more phytochrome which in turn could activate transcription factors, like PIF3 and HY5 (Shin et al. 2007), that upregulate anthocyanin biosynthesis genes.

The adult plants showed on average less fruit trusses, less fruits, and lower yield of ripe fruits per plant under LED compared to HPS (Suppl. File 3). However, when the unripe fruits at the last harvest day were included, there was no significant yield difference between HPS and LED. The average weight per fruit was a bit higher under LED, probably compensating the lower number of fruits per plant. We conclude that the plants under LED light were compacter, slower in development, but in the end produced similar yield compared to plants under HPS supplemental lighting.

\section{Conclusions}

The primary aim of this study was discovery of LEDspecific QTL for growth related traits and fruit yield. That could help plant breeders when developing 
modern cultivars that are optimal for greenhouses with supplemental LED-lighting, and developing other cultivars that are optimal for HPS supplemental light. Therefore, we developed four RIL populations, that were derived from parents that showed contrasting phenotypes under different light environments. We observed numerous QTL, both at HPS and LED supplemental lighting, at the seedling stage and at the fruiting stage. However, we detected hardly any light environment-specific QTL. Therefore, our study indicates that breeding for optimal tomato cultivars for greenhouses with supplemental HPS simultaneously leads to optimal cultivars for supplemental LED lighting. And the other way around, cultivars that perform well under LED, very likely also perform well under HPS.

Moreover, we made reciprocal crosses for the four RIL populations, in view of possible effects of the maternally inherited plastids, such as chloroplasts, and the mitochondria, which are critical for photosynthesis and energy regulation. Again, we found very clear and significant effects from the maternally inherited plastids and mitochondria, showing the importance of using a parent either as mother or as a father. However, these differences did not interact significantly with the light environment. So, similarly as for the genetic factors from the nuclei (the QTL), the genetic factors from the maternally inherited plastids and mitochondria, are of paramount importance for plant architecture and fruit traits, but these genetic factors did not show a specific interaction with either supplemental HPS or supplemental LED light.

Therefore, our data do not support tomato breeding for specific light environments in greenhouses, as far as supplemental 95\% red and 5\% blue LED light is concerned.

Acknowledgements We thank Nunhems Netherlands B.V. (BASF Vegetable Seeds), Rijk Zwaan Nederland B.V. and Bejo Zaden B.V. for developing and genotyping the RILs, and Cees Schuit and Corine de Groot (Bejo), Joost Baars, Maarten Verlaan, Maaike Wubs (Rijk Zwaan), Frank Millenaar (Nunhems), and Céline C. S. Nicole (Signify B.V.) for the useful discussions, the light design, and LED lamps. For help in the greenhouse we thank Maarten Peters, André Maassen, Sean Geurts, Geurt Versteeg, Ad Hermsen and Rohan van Genderen. Also we thank Pieter van Staalduinen (Vortus) for his tomato growing advices. For advice and help with seed material and technical instruments we gratefully like to acknowledge Jasper Vermeulen, Maarten Wassenaar, Johan Bucher, Julia van Oord, Nicole Trefflich-Luit, Joke Oosterkamp, Herman Meurs, Anton Vels and Erik Schuiling. For help with the destructive harvest we thank: Davide Palmitessa, Tijmen Kerstens, Alejandro Bustamante, Pauline Sanderson, Anton Vels, Elske Hageraats, Erik van Kranenburg, Luka van Dien, Alex van Klink, Joke Oosterkamp and Menno Bakker. Further, we thank Tijmen Kerstens and Davide Palmitessa for the light spectrum measurements of the lamps. For advice on the heritability calculation we acknowledge Chris Maliepaard (WUR) and for the advice on calculation of BLUEs we thank Peter Bourke (WUR).

Authors' contributions AEP planned the RIL experiments, and conducted and analysed the young plant experiments; HvdS helped with the planning of all the RIL experiments and the measurements; OD and SG conducted and analysed the experiment with adult plants; TO planned, conducted and analysed the initial experiment on the parents of the RILs; FM-D made the F1 hybrids for the RILs; LFMM, RGFV, EH and HJS initiated the project and contributed with discussions. All authors contributed to varying degrees in the writing of the manuscript.

Funding The presented research was funded by the Netherlands Organisation of Scientific Research (NWO), Applied and Engineering Sciences (TTW) as part of the "LED it be 50\%" program, Project Number 14211. This study was also supported by Bejo Zaden B.V., Glastuinbouw Nederland, Nunhems Netherlands B.V. (BASF Vegetable Seeds), Rijk Zwaan Nederland B.V. and Signify B.V.

Data availability The allelic marker scores and raw data are provided in the supplemental material.

Code availability Not applicable.

\section{Declarations}

Conflict of interest The authors declare that there is no conflict of interest.

Open Access This article is licensed under a Creative Commons Attribution 4.0 International License, which permits use, sharing, adaptation, distribution and reproduction in any medium or format, as long as you give appropriate credit to the original author(s) and the source, provide a link to the Creative Commons licence, and indicate if changes were made. The images or other third party material in this article are included in the article's Creative Commons licence, unless indicated otherwise in a credit line to the material. If material is not included in the article's Creative Commons licence and your intended use is not permitted by statutory regulation or exceeds the permitted use, you will need to obtain permission directly from the copyright holder. To view a copy of this licence, visit http://creativecommons.org/licenses/by/4.0/.

\section{References}

Arena C, Tsonev T, Doneva D et al (2016) The effect of light quality on growth, photosynthesis, leaf anatomy and volatile isoprenoids of a monoterpene-emitting herbaceous 
species (Solanum lycopersicum L.) and an isopreneemitting tree (Platanus orientalis L.). Environ Exp Bot 130:122-132. https://doi.org/10.1016/j.envexpbot.2016. 05.014

Bantis F, Smirnakou S, Ouzounis T et al (2018) Current status and recent achievements in the field of horticulture with the use of light-emitting diodes (LEDs). Sci Hortic 235:437-451. https://doi.org/10.1016/j.scienta.2018.02. 058

Bourke P, Hackett C, Maliepaard C et al (2021) polyqtlR: QTL analysis in autopolyploid bi-parental F1 populations. Version 0.0.6URL https://CRAN.R-project.org/package= polyqtlR

Britton CM, Dodd JD (1976) Relationships of photosynthetically active radiation and shortwave irradiance. Agric Meteorol 17:1-7. https://doi.org/10.1016/0002-1571(76) 90080-7

Broman K, Sen S (2009) A guide to QTL mapping with R/ qtl. Springer, New York

Broman KW, Wu H, Sen Ś, Churchill GA (2003) R/qtl: QTL mapping in experimental crosses. Bioinformatics 19:889-890. https://doi.org/10.1093/bioinformatics/ btg 112

Cao K, Cui L, Zhou X et al (2015) Four tomato Flowering Locus T-like proteins act antagonistically to regulate floral initiation. Front Plant Sci 6:1213. https://doi.org/10.3389/ fpls.2015.01213

Carvalho SD, Folta KM (2014) Sequential light programs shape kale (Brassica napus) sprout appearance and alter metabolic and nutrient content. Hortic Res 1:8. https://doi. org/10.1038/hortres.2014.8

Chalker-Scott L (1999) Environmental significance of anthocyanins in plant stress responses. Photochem Photobiol 70:1-9

Cong B, Barrero LS, Tanksley SD (2008) Regulatory change in YABBY-like transcription factor led to evolution of extreme fruit size during tomato domestication. Nat Genet 40:800-804. https://doi.org/10.1038/ng.144

Costigan SE, Warnasooriya SN, Humphries BA, Montgomery BL (2011) Root-localized phytochrome chromophore synthesis is required for photoregulation of root elongation and impacts root sensitivity to jasmonic acid in arabidopsis1[W][OA]. Plant Physiol 157:1138-1150. https://doi.org/10.1104/pp.111.184689

Couée I, Sulmon C, Gouesbet G, El Amrani A (2006) Involvement of soluble sugars in reactive oxygen species balance and responses to oxidative stress in plants. J Exp Bot 57:449-459. https://doi.org/10.1093/jxb/erj027

De Mendiburu F (2020) Statistical procedures for agricultural research. Version R package version 1.3-3.URL https:// CRAN.R-project.org/package $=$ agricolae

de Oliveira Silva FM, Lichtenstein G, Alseekh S et al (2018) The genetic architecture of photosynthesis and plant growth-related traits in tomato. Plant Cell Environ 41:327-341. https://doi.org/10.1111/pce.13084

Dierck R, Dhooghe E, Van Huylenbroeck J et al (2017) Light quality regulates plant architecture in different genotypes of Chrysanthemum morifolium Ramat. Sci Hortic 218:177-186. https://doi.org/10.1016/j.scienta.2017.02. 016
Eichler EE, Flint J, Gibson G et al (2010) Missing heritability and strategies for finding the underlying causes of complex disease. Nat Rev Genet 11:446-450. https://doi.org/ $10.1038 /$ nrg2809

Evers JB, van der Krol AR, Vos J, Struik PC (2011) Understanding shoot branching by modelling form and function. Trends Plant Sci 16:464-467. https://doi.org/10.1016/j. tplants.2011.05.004

Facella P, Carbone F, Placido A, Perrotta G (2016) Cryptochrome 2 extensively regulates transcription of the chloroplast genome in tomato. FEBS Open Bio 7:456-471. https://doi.org/10.1002/2211-5463.12082

Folta KM (2004) Green light stimulates early stem elongation, antagonizing light-mediated growth inhibition. Plant Physiol 135:1407-1416. https://doi.org/10.1104/pp.104. 038893

Fox J, Weisberg S (2019) An R companion to applied regression, 3rd edn. SAGE Publications Inc, Thousand Oaks (CA)

Fraser DP, Hayes S, Franklin KA (2016) Photoreceptor crosstalk in shade avoidance. Curr Opin Plant Biol 33:1-7. https://doi.org/10.1016/j.pbi.2016.03.008

Fulop D, Ranjan A, Ofner I et al (2016) A new advanced backcross tomato population enables high resolution leaf QTL mapping and gene identification. G3 GEnes Genomes Genet 6:3169-3184. https://doi.org/10.1534/g3.116. 030536

Girault T, Bergougnoux V, Combes D et al (2008) Light controls shoot meristem organogenic activity and leaf primordia growth during bud burst in Rosa sp. Plant Cell Environ 31:1534-1544. https://doi.org/10.1111/j.1365-3040.2008. 01856.x

Gómez C, Mitchell CA (2015) Growth responses of tomato seedlings to different spectra of supplemental lighting. HortScience 50:112-118. https://doi.org/10.21273/ HORTSCI.50.1.112

Gray MW (1993) Origin and, evolution of organelle genomes. Curr Opin Genet Dev 3:884-890. https://doi.org/10.1016/ 0959-437X(93)90009-E

Hernández-Bautista A, Lobato-Ortiz R, Cruz-Izquierdo S et al (2015) Fruit size QTLs affect in a major proportion the yield in tomato. Chil J Agric Res 75:402-409. https://doi. org/10.4067/S0718-58392015000500004

Hogewoning SW, Trouwborst G, Meinen E, van Ieperen W (2012) Finding the optimal growth-light spectrum for greenhouse crops. Acta Hortic 956:357-363. https://doi. org/10.17660/ActaHortic.2012.956.41

Huang Z, van der Knaap E (2011) Tomato fruit weight 11.3 maps close to fasciated on the bottom of chromosome 11 . TAG Theor Appl Genet Theor Angew Genet 123:465474. https://doi.org/10.1007/s00122-011-1599-3

Huché-Thélier L, Crespel L, Gourrierec JL et al (2016) Light signaling and plant responses to blue and UV radiationsperspectives for applications in horticulture. Environ Exp Bot 121:22-38. https://doi.org/10.1016/j.envexpbot.2015. 06.009

Ji Y, Ouzounis T, Schouten HJ et al (2020) Dissecting the genotypic variation of growth responses to far-red radiation in tomato. Front Plant Sci 11:614714. https://doi.org/10. 3389/fpls.2020.614714 
Kahlau S, Aspinall S, Gray JC, Bock R (2006) Sequence of the tomato chloroplast DNA and evolutionary comparison of solanaceous plastid genomes. J Mol Evol 63:194-207. https://doi.org/10.1007/s00239-005-0254-5

Kaiser E, Ouzounis T, Giday H et al (2019) Adding blue to red supplemental light increases biomass and yield of greenhouse-grown tomatoes, but only to an optimum. Front Plant Sci 9:2002. https://doi.org/10.3389/fpls.2018.02002

Kalaitzoglou P, van Ieperen W, Harbinson J et al (2019) Effects of continuous or end-of-day far-red light on tomato plant growth, morphology, light absorption, and fruit production. Front Plant Sci 10:322. https://doi.org/10.3389/fpls. 2019.00322

Kim HT, Lee JM (2018) Organellar genome analysis reveals endosymbiotic gene transfers in tomato. PLoS ONE 13:e0202279. https://doi.org/10.1371/journal.pone. 0202279

Kovinich N, Kayanja G, Chanoca A et al (2015) Abiotic stresses induce different localizations of anthocyanins in Arabidopsis. Plant Signal Behav 10:e1027850. https:// doi.org/10.1080/15592324.2015.1027850

Lanoue J, Leonardos ED, Ma X, Grodzinski B (2017) The effect of spectral quality on daily patterns of gas exchange, biomass gain, and water-use-efficiency in tomatoes and lisianthus: an assessment of whole plant measurements. Front Plant Sci 8:1076. https://doi.org/ 10.3389/fpls.2017.01076

Leduc N, Roman H, Barbier F et al (2014) Light signaling in bud outgrowth and branching in plants. Plants 3:223250. https://doi.org/10.3390/plants3020223

Lippman Z, Tanksley SD (2001) Dissecting the genetic pathway to extreme fruit size in tomato using a cross between the small-fruited wild species Lycopersicon pimpinellifolium and L. esculentum var. Giant Heirloom Genetics 158:413-422

Liu Z, Zhang Y, Wang J et al (2015) Phytochrome-interacting factors PIF4 and PIF5 negatively regulate anthocyanin biosynthesis under red light in Arabidopsis seedlings. Plant Sci 238:64-72. https://doi.org/10.1016/j.plantsci. 2015.06.001

Liu Y, Zhou T, Ge H et al (2016) SSR mapping of QTLs conferring cold tolerance in an interspecific cross of tomato. Int J Genomics 2016:e3219276. https://doi.org/10.1155/ 2016/3219276

Lupaşcu G, Grigorcea S, Mihnea N (2015) The influence of the maternal factor on the effects of gene involved in the control of quantitative characters in tomato. Olten Stud Si Comun Stiintele Nat 25:43-46

Mason MG, Ross JJ, Babst BA et al (2014) Sugar demand, not auxin, is the initial regulator of apical dominance. Proc Natl Acad Sci USA 111:6092-6097. https://doi. org/10.1073/pnas.1322045111

Massouh A, Schubert J, Yaneva-Roder L et al (2016) Spontaneous chloroplast mutants mostly occur by replication slippage and show a biased pattern in the plastome of oenothera. Plant Cell 28:911-929. https://doi.org/10. 1105/tpc. 15.00879

McCree KJ (1972) The action spectrum, absorptance and quantum yield of photosynthesis in crop plants. Agric Meteorol 9:191-216. https://doi.org/10.1016/0002-1571(71) 90022-7
Mohamed SM, Ali EE, Mohamed TY (2012) Study of heritability and genetic variability among different plant and fruit characters of tomato (Solanum lycopersicum L.). Int J Sci Technol Res 1:55-58

Mu Q, Huang Z, Chakrabarti M et al (2017) Fruit weight is controlled by cell size regulator encoding a novel protein that is expressed in maturing tomato fruits. PLOS Genet 13:e1006930. https://doi.org/10.1371/journal. pgen. 1006930

Nakano H, Sasaki K, Mine Y et al (2016) Quantitative trait loci (QTL) controlling plant architecture traits in a Solanum lycopersicum $\times S$. pimpinellifolium cross. Euphytica Dordr 211:353-367. https://doi.org/10.1007/ s10681-016-1744-9

Ouzounis T, Heuvelink E, Ji Y et al (2016) Blue and red LED lighting effects on plant biomass, stomatal conductance, and metabolite content in nine tomato genotypes. Acta Hortic. https://doi.org/10.17660/ActaHortic.2016.1134. 34

Oyanedel E, Wolfe DW, Owens TG et al (2000) Quantitative trait loci analysis of photoinhibition under chilling stress in tomato. Acta Hortic 521:227-232. https://doi.org/10. 17660/ActaHortic.2000.521.25

Paradiso R, Meinen E, Snel JFH et al (2011) Spectral dependence of photosynthesis and light absorptance in single leaves and canopy in rose. Sci Hortic 127:548-554. https://doi.org/10.1016/j.scienta.2010.11.017

Raime K, Remm M (2018) Method for the identification of taxon-specific k-mers from chloroplast genome: a case study on tomato plant (Solanum lycopersicum). Front Plant Sci 9:6. https://doi.org/10.3389/fpls.2018.00006

Rao AQ, Bakhsh A, Nasir IA et al (2011) Phytochrome B mRNA expression enhances biomass yield and physiology of cotton plants. Afr J Biotechnol 10:1818-1826

Revelle W (2018) psych: procedures for personality and psychological research, Northwestern University, Evanston, Illinois, USA. https://CRAN.R-project.org/package= psych

Sager JC, Smith WO, Edwards JL, Cyr KL (1988) Photosynthetic efficiency and phytochrome photoequilibria determination using spectral data. Trans ASAE 31:1882-1889. https://doi.org/10.13031/2013.30952

Savvides A, Dieleman JA, van Ieperen W, Marcelis LFM (2016) A unique approach to demonstrating that apical bud temperature specifically determines leaf initiation rate in the dicot Cucumis sativus. Planta 243:1071. https://doi. org/10.1007/s00425-015-2464-4

Sellaro R, Crepy M, Trupkin SA et al (2010) Cryptochrome as a sensor of the blue/green ratio of natural radiation in Arabidopsis. Plant Physiol 154:401-409. https://doi.org/ 10.1104/pp.110.160820

Sen S, Churchill GA (2001) A statistical framework for quantitative trait mapping. Genetics 159:371-387

Shankar A, Reddy RVSK, Sujatha M, Pratap M (2013) Genetic variability studies in F1 generation of tomato (Solanum lycopersicon L.). IOSR J Agric Vet Sci 4:31-34. https:// doi.org/10.9790/2380-0453134

Shin J, Park E, Choi G (2007) PIF3 regulates anthocyanin biosynthesis in an HY5-dependent manner with both factors directly binding anthocyanin biosynthetic gene promoters 
in Arabidopsis. Plant J Cell Mol Biol 49:981-994. https:// doi.org/10.1111/j.1365-313X.2006.03021.x

Signorelli S, Agudelo-Romero P, Meitha K et al (2018) Roles for light, energy, and oxygen in the fate of quiescent axillary buds. Plant Physiol 176:1171-1181. https://doi.org/ 10.1104/pp.17.01479

Sloan DB, Müller K, McCauley DE et al (2012) Intraspecific variation in mitochondrial genome sequence, structure, and gene content in Silene vulgaris, an angiosperm with pervasive cytoplasmic male sterility. New Phytol 196:1228-1239. https://doi.org/10.1111/j.1469-8137. 2012.04340.x

Smeekens S, Ma J, Hanson J, Rolland F (2010) Sugar signals and molecular networks controlling plant growth. Curr Opin Plant Biol 13:274-279. https://doi.org/10.1016/j.pbi. 2009.12.002

Strasser B, Sánchez-Lamas M, Yanovsky MJ et al (2010) Arabidopsis thaliana life without phytochromes. Proc Natl Acad Sci 107:4776-4781. https://doi.org/10.1073/pnas. 0910446107

Taiana T, Rashid M, Parveen S et al (2015) Selection strategies to choose better parents in tomato using genetic parameters. Plant Knowl J 4:33-39

Tucker DJ (1976) Effects of far-red light on the hormonal control of side shoot growth in the tomato. Ann Bot 40:10331042. https://doi.org/10.1093/oxfordjournals.aob.a085211

Velez-Ramirez AI, van Ieperen W, Vreugdenhil D et al (2014) A single locus confers tolerance to continuous light and allows substantial yield increase in tomato. Nat Commun 5:4549. https://doi.org/10.1038/ncomms5549

Wen J, Jiang F, Weng Y et al (2019) Identification of heattolerance QTLs and high-temperature stress-responsive genes through conventional QTL mapping, QTL-seq and RNA-seq in tomato. BMC Plant Biol 19:398. https://doi. org/10.1186/s12870-019-2008-3

Wickham H (2016) ggplot2: Elegant graphics for data analysis. Springer, New York

Williams KA, Miller CT, Craver JK (2016) Light quality effects on intumescence (oedema) on plant leaves. In: Kozai T, Fujiwara K, Runkle ES (eds) LED lighting for urban agriculture. Springer, Singapore, pp 275-286

Wolyn DJ, Borevitz JO, Loudet O et al (2004) Light-response quantitative trait loci identified with composite interval and extreme array mapping in Arabidopsis thaliana. Genetics 167:907-917. https://doi.org/10.1534/genetics. 103.024810

Yen HC, Shelton BA, Howard L et al (1997) The tomato highpigment (hp) locus maps to chromosome 2 and influences plastome copy number and fruit quality. Theor Appl Genet 95:1069-1079. https://doi.org/10.1007/s001220050 664

Yi N (2010) Statistical analysis of genetic interactions. Genet Res 92:443-459. https://doi.org/10.1017/S001667231 0000595

Zhang T, Maruhnich SA, Folta KM (2011) Green light induces shade avoidance symptoms. Plant Physiol 157:15281536. https://doi.org/10.1104/pp.111.180661

Publisher's Note Springer Nature remains neutral with regard to jurisdictional claims in published maps and institutional affiliations. 